\title{
Limited Investor Attention and Stock Market Misreactions to Accounting Information
}

\author{
David Hirshleifer \\ Paul Merage School of Business, University of California
}

Sonya S. Lim

Department of Finance, DePaul University

Siew Hong Teoh

Paul Merage School of Business, University of California

\begin{abstract}
We provide a model in which a single psychological constraint, limited attention, explains both under- and overreaction to different earnings components. Investor neglect of earnings induces post-earnings announcement drift and the profit anomaly. Neglect of earnings components causes accrual and cash flow anomalies. The model offers empirical implications relating the strength of earnings-related anomalies to the forecasting power of current earnings-related information for future earnings, investor attentiveness, and the volatilities of and correlation between accruals and cash flows. We also show that, owing to attention costs, in equilibrium not all investors choose to attend to earnings or its components. (JEL G12, G14, M41, M43)
\end{abstract}

Market reactions to earnings and earnings components present a striking puzzle. Stock prices on average underreact to earnings surprises (post-earnings announcement drift), but overreact to the operating accruals component of earnings. ${ }^{1}$ Earnings- and accruals-related patterns of return predictability are often referred to as "anomalies," "under-" and "overreaction," or reflecting investor "optimism," "pessimism," or "naïveté." Such labels offer little guidance as to the sources of these effects. Furthermore, a procedure of conjecturing a separate psychological bias for each misreaction pattern creates a problem of model overfitting; explanatory power is bought at the expense of predictive power.

\footnotetext{
Formerly entitled "Limited Investor Attention and Earnings-related Under- and Overreaction," this article was presented at the American Accounting Association Annual Meetings in San Francisco. We thank an anonymous referee, Jennifer Altimuro (the conference discussant), Peng-Chia Chiu, Phil Davies, Tim Haight, Danling Jiang, Kuan-Hui Lee, Rose Liao, Dong Lou, Angie Low, Jeffrey Pontiff (the editor), Lin Sun, and Yinglei Zhang for helpful discussions and comments. Send correspondence to Siew Hong Teoh, The Paul Merage School of Business, University of California, Irvine, CA 92697-3125; telephone: (949) 824 9952. E-mail: steoh@uci.edu.

1 Evidence of post-earnings announcement drift is provided by Ball and Brown (1968) and Bernard and Thomas (1989); on the accrual and cash flow anomalies, see Sloan (1996) and Collins and Hribar (2000). Most empirical tests that control for possible risk factors have not supported a rational risk premium explanation for these return patterns (see the abovementioned studies).
}

(C) The Author 2011. Published by Oxford University Press on behalf of The Society for Financial Studies. All rights reserved. For Permissions, please e-mail: journals.permissions@oup.com. doi:10.1093/rapstu/rar002

Advance Access publication July 27, 2011 
We explore here the implications of a single well-established psychological constraint, limited investor attention, for the ability of earnings and earnings components to forecast abnormal returns. We argue that limited attention offers a parsimonious explanation for both under- and overreaction to earnings and earnings components. The model of limited attention that we provide is consistent with post-earnings announcement drift, the accrual anomaly, the cash flow anomaly, and the profit anomaly. In addition to providing an integrated approach to earnings-related anomalies, our model offers new empirical implications about the determinants of the strength of mispricing effects. Specifically, we derive new, untested implications for how return predictability is related to the volatilities, correlation between, and earnings forecasting power of these components and the degree of investor attention to earnings-related information.

Attention requires effort and, since the amount of information available is vast, must be selective (e.g., Kahneman 1973). There is evidence from the experimental laboratory that limited attention affects how both naïve and sophisticated individual investors, as well as financial professionals, interpret accounting data (see the review of Libby, Bloomfield, and Nelson 2002). Such evidence suggests that attentional constraints may be a source of investor misvaluation of accounting information.

Several kinds of evidence suggest that limited investor attention contributes to post-earnings announcement drift. Market reactions to earnings surprises are muted when the news is released to the media during low-attention periods. After-hours earnings announcements are impounded into price gradually in the days after the disclosure (Francis, Pagach, and Stephan 1992). The volume reaction and two-day stock price reaction to news that is released to the media on Fridays and on days with many competing announcements are weaker, and post-earnings announcement drift is stronger, than when news is released on other days of the week and on days with few competing announcements (DellaVigna and Pollet 2009; Hirshleifer, Lim, and Teoh 2009).

Evidence also suggests that limited investor attention may play a role in the accrual anomaly. Institutional investors, as professionals, should be more attentive to earnings components than individuals. Consistent with this, the accrual anomaly is stronger among stocks with lower ownership by active institutional investors (Collins, Gong, and Hribar 2003). Furthermore, managers seem to use their accounting discretion to exploit investors' neglect of accruals information (e.g., Teoh, Welch, and Wong 1998a,b; DeGeorge, Patel, and Zeckhauser 1999) and there is evidence that firms' abnormal accruals are misvalued (Teoh, Welch, and Wong 1998a,b). Analysts, whether for agency or psychological reasons, tend to neglect accruals information in forming their forecasts (Teoh and Wong 2002). Finally, the accrual anomaly is not present among the subset of firms that disclose the level of accruals at the date of the original earnings announcement (Chen, DeFond, and Park 2002). This suggests that the accrual anomaly is caused by those investors who attend 
to the earnings announcement but not to the later financial reporting of accruals.

Contributing to a focus on earnings by both individual investors and financial professionals, the business media discuss earnings much more than cash flow and accruals numbers. As related by the well-known stock analyst Abby Joseph Cohen, "Many participants in the investment business still rely on EPS [earnings per share], to the exclusion of important measures of firm performance, such as revenues and cash flow..." (Cohen 2005, p. 30). This emphasis is useful for investors with limited attention and processing power. If an investor must select between earnings and cash flow to focus upon, the best choice is the signal that is most informative about firm value. Empirically, stock returns are more strongly related to news about contemporaneous earnings than about cash flow (Dechow 1994). Nevertheless, since cash flow is incrementally informative relative to earnings, the neglect of how earnings is divided between cash flow and accruals causes systematic bias.

In our model, investors with limited attention condition on different subsets of publicly available earnings-related signals in valuing a stock. Risk-averse investors who are fully attentive to the relevant information item are willing to bear only a limited amount of risk in order to exploit mispricing. Thus, equilibrium stock prices reflect a weighted average of the beliefs of investors who attend to different signals, with weights that depend on the relative numbers in each investor group and their risk tolerances; see also the discussion in footnote 6 . This approach, which is by now familiar, serves as the building block for our new findings about the effects of limited attention toward earnings and earnings components.

In the model, some investors attend to the implications of current-period earnings for future prospects, and a subset of these investors also attend separately to the accrual and cash flow components of earnings. (Further motivation of the assumption that some investors neglect earnings information is provided in Sections 1 and 4.) Using the signals they attend to, investors form valuations of the firm. In equilibrium, prices underreact to earnings surprises because of the subset of investors who do not incorporate this information into their expectations of future earnings.

Investors who do attend to earnings but do not distinguish between earnings components misvalue firms with abnormal levels of accruals. Empirically, the level of accruals is a less favorable forecaster than cash flow of firm profitability (Sloan 1996). Regardless of whether this difference in forecasting power is a consequence of earnings management or of the general nature of the accounting system, a rational investor should take this fact into account in valuing firms. In our model, an investor who attends to earnings but does not impound the information in earnings components into his valuation overvalues high-accruals firms and undervalues low-accruals firms. Since misvaluation is eventually corrected, this effect can, under appropriate conditions, cause high accruals to predict low subsequent abnormal returns, and high cash flows to 
predict high subsequent abnormal returns. Thus, the analysis reconciles underreaction to earnings with overreaction to accruals.

Using this framework, we provide new empirical implications about the direction and strength of the forecasting power of earnings surprises, accruals, and cash flow for future returns. The intuition starts from the fact that, conditional upon high accruals, contemporaneous earnings also tend to be high, which causes investors to forecast higher future earnings. In this situation, an investor who attends to earnings but neglects accruals is overoptimistic because he forecasts high future earnings based upon high current-period earnings. When cash flow is high, an individual who neglects this fact is overpessimistic (even if he also neglects earnings).

These effects imply that the direction and strength of accruals or cash flows as return predictors depend on how favorably these variables predict future earnings relative to the forecasting power of current-period earnings as a predictor of future earnings, and on what information investors neglect. The predictive powers of these variables for future earnings are influenced by the relative variability of cash flows and accruals, the correlation of these earnings components, and the quality of accruals. In consequence, the more variable the accruals relative to cash flows, the stronger the cash flow anomaly relative to the accrual anomaly; higher correlation between cash flows and accruals tends to weaken the accrual anomaly; and lower quality of accruals (a weaker incremental ability of accruals to forecast future earnings) tends to strengthen the accrual anomaly.

When some investors neglect earnings, and others attend to earnings but neglect accruals, stock prices underreact to earnings, and overreact to accruals relative to cash flow. If enough attention is paid to earnings, the relative overreaction to accruals outweighs the general underreaction to earnings, so that overall price overreacts to accruals. In consequence, the conditions for the accrual anomaly to exist in our model differ from that suggested by Sloan (1996), that accruals be a stronger forecaster than cash flows of future earnings. Furthermore, we show that there tends to be stronger underreaction to cash flow than to earnings; the ratio of the cash flow effect on returns to the accruals effect on returns is greater in absolute value than the ratio of the variance of accruals to the variance of cash flow.

We also show that, owing to investor neglect of the implications of earnings news for future earnings, the current level of earnings predicts stock returns even after controlling for the current earnings surprise. Thus, the model explains the profit anomaly (Balakrishnan, Bartov, and Faurel 2010; Chen, NovyMarx, and Zhang 2010). The demands of inattentive investors are based on prior beliefs about expected future earnings as reflected in indicators such as the previous year's earnings or analyst forecasts of the current year's earnings. These indicators are less accurate than realized current-year earnings as predictors of future earnings. Thus, mispricing is correlated with the current level of earnings. 
Finally, we consider a setting where individuals decide the level of attention by balancing the cost of attention against the expected benefits. We show that, in equilibrium, some investors may decide not to attend to the implications of public information about earnings or its components. This analysis explains why inattentive investors who trade based upon their inattentive expectations (rather than simply remaining on the sidelines) can survive in the long run.

A recent theoretical literature examines how constraints on information processing affect investor behavior. Our approach here is similar in spirit to that of Hirshleifer and Teoh (2003), who study the effects on market prices of investors neglecting relevant accounting information or strategic aspects of the disclosure and reporting environment. A key difference is that we examine here the implications of limited attention for market misvaluation in relation to earnings surprises, the level of earnings, accruals, and cash flows. Other recent papers model the allocation of attentional resources (Gabaix and Laibson 2005; Peng 2005; Hirshleifer, Lim, and Teoh 2008), how limited learning capacity affects asset price comovement (Peng and Xiong 2006) and the speed of price adjustment to fundamental shocks (Peng 2005; Peng and Xiong 2006), how delayed processing of new information affects the dynamics of asset price volatility (Peng and Xiong 2002), how neglect of demographic information affects asset prices (DellaVigna and Pollet 2007), and how informed parties make disclosure decisions when observers have limited attention (Hirshleifer, Lim, and Teoh 2008).

\section{The Economic Setting}

There are three types of investors in the model: those who ignore all current earnings-related information, those who attend only to a subset of that information, and those who attend to all publicly available information. All investors are ex ante identical, and differences in how much of the public information set they process depend on the cost they have incurred to obtain information. We assume that inattentive investors, apart from the specific signals they ignore, update beliefs as rational Bayesians.

There are two dates. At date 1 , cash flow $c_{1}$, accruals $a_{1}$, and earnings $e_{1}=c_{1}+a_{1}$ are realized. Investors update their prior beliefs based on whatever public signals they observe. At date 2, terminal earnings, cash flows, and accruals, $e_{2}, c_{2}$, and $a_{2}$, are realized, where $e_{2}=c_{2}+a_{2}$, and the firm is liquidated. In general, accounting accruals must reverse out, so we assume that $a_{2}=-a_{1}$.

Prices are set by trading in a securities market with no private information, so that a rational individual has nothing to learn from market price. An inattentive individual who is unaware of his signal neglect will also think he has nothing to learn from market price. We therefore assume that inattentive investors 
do not update their beliefs based on market price. ${ }^{2}$ Similar results would hold as long as some disagreement remains between the attentive and inattentive investors, i.e., inattentive investors do not always completely abandon their beliefs in favor of the information implicit in the market price.

Nevertheless, if an investor understood his attentional limits, a discrepancy between an investor's valuation and the market price could alert the investor to his information neglect. The investor in principle could then correct this neglect by deferring to the belief implicit in market price. In general, however, the same constraints on processing power and memory that make it hard to attend to some public signal also make it hard to use price or other indicators to compensate optimally for the failure to attend to it. ${ }^{3}$ For example, an investor may just not think about the source of the discrepancy between the market price and his own valuation. As long as some fraction of inattentive investors have imperfect self-awareness, results similar to those derived here will obtain.

Furthermore, even if individuals always attend to market price and are fully aware of their information neglect, similar results to those we derive here could be obtained as long as there is "noise" in market price arising from liquidity trading. In such a setting, an individual who attends to a given public signal in effect has a sort of "private" information, so different individuals who attend to different public signals will trade and profit at the expense of liquidity traders, in the spirit of the models of Grossman and Stiglitz (1976) and Diamond and Verrecchia (1981). This approach is discussed more fully in Section 4.

In general, attending to more information is costly. Since investors have finite cognitive resources, attending to some information implies less time and resources for other activities. We assume that there are different investor groups indexed by $i$ who attend to different information sets. Fully attentive investors attend to all date 1 publicly available information; investors with limited attention attend to subsets of date 1 public information. The decision to incur a cost to attend to the information set precedes the trading decision. At this stage, we focus on the trade decision at date 1, taking the information set as given. Later in Section 3.2, we analyze the decision of how much information an individual attends to if there is an associated cost.

We assume that investors have a mean-variance utility function,

$$
E^{i}\left[C_{2}^{i}\right]-\left(\frac{A}{2}\right) \operatorname{var}^{i}\left(C_{2}^{i}\right),
$$

where $C_{2}^{i}$ is terminal consumption, $A$ is the coefficient of absolute risk aversion, and $i$ superscripts denote the expectation or variance as formed by group $i$.

2 Observing the "wrong" price is an event which, as perceived by the investor, is not supposed to occur in equilibrium. In the Perfect Bayesian Equilibrium concept of game theory setting, the individual's posterior beliefs in such a situation equal to the prior belief can be consistent with equilibrium.

3 Section 4 discusses evidence suggesting that individuals fail to compensate fully for the consequences of limited attention in making decisions. 
We assume that the decision-making investors have an initial wealth endowment (i.e., claims to terminal consumption) of $W$, and zero shares of the risky security. In addition, mechanistic noise traders bring to the market a stochastic per-capita supply of the single risky security of $x_{0}$ (i.e., supply per member of the decision-making population), which is normally distributed with mean zero and variance $V_{x}$, uncorrelated with the other exogenous random variables (earnings and its components). ${ }^{4}$ At date 1 , the individual can buy or sell the security in exchange for "cash" (claims to terminal consumption) at price $S_{1}$. The position in the security he attains is denoted $x^{i}$. Let $S_{2}$ be the true value of the stock, which is conclusively revealed to all at date 2 . Then, letting $k^{i}$ be the cost of attending to the information set used by attention group $i$, the consumption of an individual in group $i$ is

$$
C_{2}^{i}=W-k^{i}+x^{i}\left(S_{2}-S_{1}\right) .
$$

Thus, an individual in attention group $i$ solves

$$
\max _{x^{i}} x^{i}\left(E^{i}\left[S_{2}\right]-S_{1}\right)-\left(\frac{A}{2}\right) \operatorname{var}^{i}\left(x^{i} S_{2}\right) .
$$

As a preliminary building block, we verify in our setting a standard finding about stock prices as a weighted average of investor expectations of terminal cash flows as adjusted by a risk premium. Differentiating the objective with respect to $x^{i}$, equating to zero and solving yields

$$
x^{i}=\frac{E^{i}\left[S_{2}\right]-S_{1}}{\operatorname{Avar}^{i}\left(S_{2}\right)} .
$$

In several behavioral models, there are both rational and imperfectly rational investors who are risk averse and who maximize their expected utilities with respect to their correct or incorrect beliefs. In this literature, prices in equilibrium reflect a weighted average of the valuations of the rational and irrational traders. Even if there are no market imperfections, both groups influence prices significantly owing to the finite risk-bearing capacity of each group.

Letting $f^{i}$ denote the fraction of investors in attention group $i$, the security price is determined by the market clearing condition

$$
\sum_{i} f^{i} x^{i}=x_{0}
$$

Substituting for $x^{i}$ from (4) and solving for $S_{1}$ gives

$$
S_{1}=\frac{\sum_{i} \lambda^{i} E^{i}\left[S_{2}\right]-A x_{0}}{\sum_{i} \lambda^{i}},
$$

\footnotetext{
4 For most of the article, it is not necessary that $x_{0}$ be stochastic. However, in Section 3, "noise" or "liquidity" trading is needed for inattentive investors to earn positive expected profits from trading. As in Grossman and Stiglitz (1976), noise creates scope for other investors to earn expected profits from trading.
} 
where

$$
\lambda^{i} \equiv \frac{f^{i}}{\operatorname{var}^{i}\left(S_{2}\right)} .
$$

By normality, the $\lambda^{i}$ s are constants independent of the signal realizations used by investors to condition beliefs.

This confirms that, in equilibrium, prices are a weighted average of the beliefs about terminal cash flows of different investors adjusted by a risk premium $\left(A x_{0} / \sum_{i} \lambda^{i}\right)$, with weight $\lambda^{i} / \sum_{i} \lambda^{i}$ on each information set. By (7), ceteris paribus $\lambda^{i}$ is increasing in $f^{i}$. Thus, the greater the likelihood of each investor being inattentive, the greater the weight that inattentive investors play in determining prices.

To focus on the effect of investor attention on investor mean beliefs, we follow the heuristic trading approach of Verrecchia (2001), in which the biases of traders are manifested in their expectations (first moments) but not second moments. So, for tractability, we model the expectations of attentive and inattentive investors (6) as depending on $i$, but the variances in (7) as independent of $i, \operatorname{var}^{i}\left(S_{2}\right)=\operatorname{var}\left(S_{2}\right) .^{5}$

So, the equilibrium price simplifies to

$$
S_{1}=\sum_{i} f^{i} E^{i}\left[S_{2}\right]-A \operatorname{var}\left(S_{2}\right) x_{0}
$$

In this setting, rational investors exploit a trading strategy that earns predictable abnormal returns, relative to a fully rational asset pricing benchmark. Nevertheless, even though markets are perfect and there are no restrictions on either long positions or short-selling, fully attentive investors do not completely arbitrage away the mispricing generated by inattentive investors. The reason they do not is because doing so is risky.

The intuition behind the traditional notion that rational investors dominate price is that rational investors trade to arbitrage away mispricing. However, if prices were set solely by the rational investors, imperfectly rational investors would perceive a profit opportunity to trade against what they regard as mispricing. If all investors are risk averse, the equilibrium outcome reflects a weighted average among these beliefs. ${ }^{6}$

5 It is not essential that the groups all assess variance as the unconditional variance; for example, all results would still hold if variance were assessed as the variance conditional upon all the available public signals. If we relaxed this assumption, the algebra would become more complicated, but the broad conclusion would still hold that limited investor attention reconciles underreaction in the form of post-earnings announcement drift with overreaction in the form of the accrual anomaly. One limitation of the assumption, however, is that comparative statics on the effects of shifts in attention will more generally also be influenced by the effect of attention on perceived risk.

6 Weighted average forms are found in previous models; see, for example, Kandel and Pearson (1995), who provide evidence supportive of prices reflecting average trader perceptions; and in the context of limited attention, Hirshleifer and Teoh (2003). 


\section{The Accrual Anomaly and Post-earnings Announcement Drift}

The next subsection describes the basic structure of cash flow, earnings, and accruals over time. Subsection 2.2 establishes that there is post-earnings announcement drift. Subsection 2.3 shows that the same setting also generates overreaction to the accruals component of earnings, and that cash flows positively predict subsequent abnormal returns. Subsection 2.4 derives new empirical predictions about the circumstances in which the accrual and cash flow anomalies will be stronger or weaker. Subsection 2.5 shows that limited attention also provides an explanation for the profit anomaly, the predictability of returns based upon the level of earnings.

\subsection{The relation of earnings, accruals, and cash flow over time}

Suppose that, at date 1 , fraction $f^{u}$ of investors ignore current-period earnings $e_{1}$ and remain at their prior belief, ${ }^{7}$ that fraction $f^{e}$ of investors attend to earnings $e_{1}$ but not to accruals and cash flow separately, and that the remaining fraction $f^{a} \equiv 1-f^{u}-f^{e}$ attend to both accruals and cash flow and therefore fully take into account the information in earnings, since

$$
e_{1}=c_{1}+a_{1} \text {. }
$$

Then, by Equation (8), the date 1 stock price is

$$
S_{1}=f^{u} E\left[S_{2}\right]+f^{e} E\left[S_{2} \mid e_{1}\right]+f^{a} E\left[S_{2} \mid a_{1}, c_{1}\right]-A \operatorname{var}\left(S_{2}\right) x_{0} .
$$

For tractability, we assume multivariate normality of the stochastic variables. As a result, date 2 earnings can be expressed as a linear function of the date 1 variables $a_{1}$ and $c_{1}$ and a noise term $\delta$ as

$$
e_{2}=\beta_{0}+\beta_{1} c_{1}+\beta_{2} a_{1}+\delta,
$$

where $\operatorname{cov}\left(\delta, c_{1}\right)=\operatorname{cov}\left(\delta, a_{1}\right)=0$. Consistent with past empirical evidence (Sloan 1996), we assume that cash flow is a more positive predictor of future earnings than accruals, $\beta_{1}>\beta_{2}>0 .{ }^{8}$ Since earnings $e_{1}=a_{1}+c_{1}$, Equation (11) directly implies that, in a regression of future earnings $e_{2}$ on current period earnings and accruals, there is a negative coefficient on $a_{1}$. Similarly, in a regression of future earnings on current-period earnings and cash flow, there is a positive coefficient on cash flow.

Letting bars denote unconditional expectations, by (11) we have

$$
\bar{e}_{2}=\beta_{0}+\beta_{1} \bar{c}_{1}+\beta_{2} \bar{a}_{1},
$$

7 It is not essential for the main conclusions of this article that these investors completely ignore earnings. They could attend to the direct effect but ignore the positive implications of higher immediate earnings for future earnings. Taking this into account would slightly modify the algebra but would not substantively affect the model's qualitative predictions.

8 An extra unit of either cash flow or accruals at date 1 increases date 1 earnings by one dollar. Thus, precisely because $\beta_{1}>\beta_{2}>0$, expected firm value $E\left[S_{2} \mid a_{1}, c_{1}\right]=E\left[e_{1}+e_{2} \mid a_{1}, c_{1}\right]$ increases more when cash flow increases by one dollar than when accruals does. 
so the deviation of earnings from its unconditional mean is

$$
e_{2}-\bar{e}_{2}=\beta_{1}\left(c_{1}-\bar{c}_{1}\right)+\beta_{2}\left(a_{1}-\bar{a}_{1}\right)+\delta .
$$

The terminal realized value of the stock is the sum of the cash flows at the two periods. Under clean surplus accounting, this is also equal to the sum of the earnings, so

$$
\begin{gathered}
S_{2}=c_{1}+c_{2}=e_{1}+e_{2} \\
E\left[S_{2}\right]=\bar{e}_{1}+\bar{e}_{2}=\bar{c}_{1}+\bar{c}_{2} .
\end{gathered}
$$

High earnings at date 1 is linearly associated with high earnings at date 2 . The strength of this relation is given by the regression coefficient, which by (9) and (11) is

$$
\begin{aligned}
\beta_{e_{2} e_{1}} & =\frac{\operatorname{cov}\left(\beta_{1} c_{1}+\beta_{2} a_{1}+\delta, c_{1}+a_{1}\right)}{V_{e_{1}}} \\
& =\left(\frac{V_{c}+C}{V_{c}+V_{a}+2 C}\right) \beta_{1}+\left(\frac{V_{a}+C}{V_{c}+V_{a}+2 C}\right) \beta_{2},
\end{aligned}
$$

where $C \equiv \operatorname{cov}\left(a_{1}, c_{1}\right)$, and where $V$ denotes the variance of a variable, with the abbreviations $V_{a}$ for $V_{a_{1}}$ and $V_{c}$ for $V_{c_{1}}$.

Thus, $\beta_{e_{2} e_{1}}$ is a weighted average of $\beta_{1}$ and $\beta_{2}$. Since $\beta_{1}>\beta_{2}$, it follows that $\beta_{1}>\beta_{e_{2} e_{1}}>\beta_{2}$ so long as both weights are positive. Both weights are positive under the assumption that each of higher accruals and higher cash flow is associated with higher contemporaneous earnings.

$$
\begin{aligned}
& \operatorname{cov}\left(e_{1}, c_{1}\right)=V_{c}+C>0 \\
& \operatorname{cov}\left(e_{1}, a_{1}\right)=V_{a}+C>0 .
\end{aligned}
$$

This is plausible; accruals and cash flows are components of earnings, and empirical studies have documented that earnings is positively correlated with accruals and cash flows (e.g., Dechow and Ge 2006; Pincus, Rajgopal, and Venkatachalam 2007).

We also assume that accruals are positively related to the sum of date 1 and date 2 earnings,

$$
\operatorname{cov}\left(e_{1}+e_{2}, a_{1}\right)=\left(1+\beta_{2}\right) V_{a}+\left(1+\beta_{1}\right) C>0 .
$$

This assumption is intuitively obvious; it requires that accounting adjustments not be completely meaningless, so that a higher accrual is on average associated with higher long-run total firm value, $e_{1}+e_{2}$. For example, as discussed above, earnings and accruals are positively contemporaneously correlated, so a sufficient condition for this to hold is that accruals be positively correlated 
with future earnings, $\operatorname{cov}\left(e_{2}, a_{1}\right)>0$. Although Sloan (1996) finds that the accrual component of earnings is less persistent than the cash flow component, his estimates also indicate that high accruals are associated with higher future earnings. ${ }^{9}$ Furthermore, condition (17) is also essentially equivalent (under efficient markets) to the finding of Dechow (1994) that stock returns covary more strongly with innovations in earnings than cash flows. ${ }^{10}$

Under these conditions, (15) indicates that high current-period cash flow is a more favorable forecaster of future earnings than is high current-period earnings, which in turn is a more favorable forecaster than high current-period accruals. It follows that the relation between date 2 and date 1 earnings is stronger the more variable are cash flows relative to accruals.

\subsection{Post-earnings announcement drift}

We next examine the relation between the date 1 earnings surprise and expected future abnormal stock returns. We define the earnings surprise as $e_{1}-\bar{e}_{1}$, where $\bar{e}_{1}$ is the prior expectation of date 1 earnings. Since $\bar{e}_{1}$ is a constant, conditioning on the earnings surprise is equivalent to conditioning on the date 1 earnings $e_{1}$. We begin by calculating, conditional on earnings $e_{1}$, the expected future value of the stock $E\left[S_{2} \mid e_{1}\right]$. For tractability, we examine price changes rather than percentage returns, as is standard in much of the literature on information in securities markets (see, e.g., Verrecchia 2001; Peng 2005). Using standard properties of conditional expected values with multivariate normal distributions,

$$
\begin{aligned}
E\left[S_{2} \mid e_{1}\right] & =e_{1}+E\left[e_{2} \mid e_{1}\right] \\
& =e_{1}+\bar{e}_{2}+\left(e_{1}-\bar{e}_{1}\right) \beta_{e_{2} e_{1}}=E\left[S_{2}\right]+\left(1+\beta_{e_{2} e_{1}}\right)\left(e_{1}-\bar{e}_{1}\right) .
\end{aligned}
$$

To calculate the conditional expected return given $e_{1}$, we also need $E\left[S_{1} \mid e_{1}\right]$. Drift in our model means that the expected change in the stock price conditional on the earnings surprise increases with $e_{1}$, with zero effect when realized earnings is equal to its prior expectation. We calculate the expected post-event return as

$$
E\left[S_{2}-S_{1} \mid e_{1}\right]=E\left[S_{2} \mid e_{1}\right]-E\left[S_{1} \mid e_{1}\right]
$$

9 In a regression of one-year-ahead earnings on accruals and cash flows, Sloan (1996) and Dechow and Ge (2006) report that the coefficients on both variables are significantly positive.

10 Since $e_{1}+e_{2}$ is total firm value, the covariance in (17) is $\operatorname{cov}\left(e_{1}+e_{2}, e_{1}-c_{1}\right)=\operatorname{cov}\left(e_{1}+e_{2}, e_{1}\right)-\operatorname{cov}\left(e_{1}+\right.$ $\left.e_{2}, c_{1}\right)$. By the law of iterated expectations, this last expression is equal to $\operatorname{cov}\left(E\left[e_{1}+e_{2}\right], e_{1}\right)-\operatorname{cov}\left(E\left[e_{1}+\right.\right.$ $\left.\left.e_{2}\right], c_{1}\right)$, where the inner expectation is conditional on all publicly available date 1 information. In an efficient market, the inner expectation is just the stock price, so if $\operatorname{cov}\left(S_{1}, e_{1}\right)-\operatorname{cov}\left(S_{1}, c_{1}\right)>0$ (which is basically the Dechow finding, since at date 0 any prior level of earnings, cash flows, or stock price is constant), then (17) holds. In our model, markets are not efficient, but as long as some investors are attentive to earnings components, the general point still holds that, ceteris paribus, a tendency of high accruals to covary positively with total firm value will tend to increase the covariance of stock returns with earnings as compared to cash flow. 
An iterated conditional expectation where one conditioning information set is coarser than the other is equivalent to a single expectation conditional on the coarser information set (e.g., Ash 1972, Theorem 6.5.10). Since $e_{1}=a_{1}+c_{1}$, the information provided by $e_{1}$ is coarser than that provided by $\left(a_{1}, c_{1}\right)$, so

$$
E\left[E\left[S_{2} \mid a_{1}, c_{1}\right] \mid e_{1}\right]=E\left[S_{2} \mid e_{1}\right]
$$

$E\left[S_{2} \mid e_{1}\right]$ is given in Equation (18). It follows from (10) and (18) that the expected return after earnings announcement is

$$
\begin{aligned}
E\left[S_{2}-S_{1} \mid e_{1}\right] & =E\left[S_{2} \mid e_{1}\right]-\left\{f^{u} E\left[S_{2}\right]+\left(f^{e}+f^{a}\right) E\left[S_{2} \mid e_{1}\right]\right\} \\
& =f^{u}\left(E\left[S_{2} \mid e_{1}\right]-E\left[S_{2}\right]\right) \\
& =f^{u}\left(1+\beta_{e_{2} e_{1}}\right)\left(e_{1}-\bar{e}_{1}\right) .
\end{aligned}
$$

We can define misvaluation in the current stock price as the difference between $S_{1}$ and $S_{1}^{*}$, the price that would be set if all investors were attentive $\left(f^{a}=1\right)$. From (10) and (20), $E\left[S_{1}^{*} \mid e_{1}\right]=E\left[E\left[S_{2} \mid a_{1}, c_{1}\right]-A \operatorname{var}\left(S_{2}\right) x_{0} \mid e_{1}\right]=E\left[S_{2} \mid e_{1}\right]$. Therefore, since $E\left[S_{1}^{*}-S_{1} \mid e_{1}\right]=E\left[S_{2}-S_{1} \mid e_{1}\right]$, there is over (under)-valuation if and only if the expected price change is negative (positive).

From (10), the average immediate price reaction to the date 1 earnings announcement conditional upon an earnings realization $e_{1}$ is

$$
\begin{aligned}
E\left[S_{1} \mid e_{1}\right]-E\left[S_{1}\right] & =\left(1-f^{u}\right)\left(E\left[S_{2} \mid e_{1}\right]-E\left[S_{2}\right]\right) \\
& =\left(1-f^{u}\right)\left(1+\beta_{e_{2} e_{1}}\right)\left(e_{1}-\bar{e}_{1}\right) .
\end{aligned}
$$

This proves:

\section{Proposition 1.}

1. If fraction $f^{u}>0$ of investors neglect the information in current-period earnings as well as cash flow and accruals, then more positive earnings surprises are associated with greater undervaluation of the firm, and more negative surprises with greater overvaluation; and there is postearnings announcement drift.

2. The average immediate price reaction to the earnings surprise, the extent to which the firm is undervalued (or less overvalued), and average post-event abnormal returns increase with the earnings surprise, $e_{1}-\bar{e}_{1}$.

3. The strength of the post-earnings announcement drift anomaly, and the sensitivity of misvaluation and the average immediate price reaction to the earnings surprise, increase with the persistence of earnings, $\beta_{e_{2} e_{1}}$. 
4. The higher the fraction of investors who neglect earnings information, $f^{u}$, the weaker the average immediate reaction to a given earnings surprise, the stronger the relation of misvaluation to the earnings surprise, and the stronger the post-earnings announcement drift.

As a special case, suppose that earnings follows a random walk, and consider a previous date 0 at which time the firm earns $e_{0}=\bar{e}_{1}$. Then, the surprise is the change in earnings, $e_{1}-e_{0}$. So, the above predictions can be applied to one-year changes in earnings.

A recent body of research provides evidence that is generally supportive of the persistence prediction of Part 3. Livnat (2003) provides evidence that higher earnings persistence is associated with stronger drift, consistent with Part 3 of Proposition 1. Furthermore, since revenues have greater persistence than expenses, drift should be especially strong if the earnings surprise comes largely from a surprise in revenues (Jegadeesh and Livnat 2006). Gu, Jain, and Ramnath (2005) and Jegadeesh and Livnat (2006) find that analyst forecasts also do not fully reflect differences in persistence between revenues and expenses. Chen (2009) finds, consistent with the prediction in Part 3, that drift is strongest among high-persistence firms, but reports a reverse drift relation for firms with very low persistence, a phenomenon our model does not explain.

Part 4 of Proposition 1 implies that the immediate price reaction is weaker and drift is stronger when a greater fraction $f^{u}$ of investors are inattentive to earnings. Possible proxies for inattention to earnings include the occurrence of earnings announcements on Fridays (DellaVigna and Pollet 2009), a high number of earnings announcements competing for attention (Hirshleifer, Lim, and Teoh 2009), an announcement after trading hours (Bagnoli, Clement, and Watts 2005), and low amounts of accounting-related discussion at the times of earnings announcements (Lerman 2011). For these proxies, Part 4 is consistent with the evidence discussed in the introduction that there is weaker average immediate reaction to earnings news and stronger drift when attention is weaker. For a given size of the earnings surprise, a greater neglect of earnings in our model causes a weaker immediate reaction to earnings news, and a greater long-term reaction (drift). In addition, attention to earnings is likely to increase with investor sophistication. If institutional holdings are viewed as a proxy for investor sophistication, then this implication is consistent with the evidence that firms whose shares are held heavily by individuals instead of institutions have stronger drift (Bartov, Krinsky, and Radhakrishnan 2000).

The empirical implications of Proposition 1 regarding under- and overvaluation can be tested using contemporaneous misvaluation measures. For example, the residual income model of Ohlson (1995) provides a contemporaneous measure of fundamental firm value. As a result, the ratio of market price to the residual income model valuation provides a measure of misvaluation (as applied, for example, by Lee, Myers, and Swaminathan 1999; Dong, Hirshleifer, Richardson, and Teoh 2006). 


\subsection{The accruals and cash flow anomalies}

We now examine whether accruals or cash flows are forecasters of future returns. ${ }^{11}$ Specifically, we examine whether, conditional on the level of accruals (or cash flows), the stock is mispriced, thereby implying subsequent abnormal returns. To do so, we calculate the expectation of the date 2 value of the stock conditional on accruals, $E\left[S_{2} \mid a_{1}\right]$, and of the date 1 stock price conditional on accruals, $E\left[S_{1} \mid a_{1}\right]$. The difference between these two values is the expected price change conditional on the level of accruals.

It follows from a property of conditional expectations (e.g., Ash 1972) that

$$
E\left[E\left[S_{2} \mid a_{1}, c_{1}\right] \mid a_{1}\right]=E\left[S_{2} \mid a_{1}\right],
$$

as the information in $a_{1}$ is coarser than that in $\left(a_{1}, c_{1}\right)$. So, the expected price change conditional on accruals $a_{1}$ is

$$
\begin{aligned}
E\left[S_{2}-S_{1} \mid a_{1}\right] & =E\left[S_{2} \mid a_{1}\right]-\left(f^{u} E\left[S_{2}\right]+f^{e} E\left[E\left[S_{2} \mid e_{1}\right] \mid a_{1}\right]+f^{a} E\left[S_{2} \mid a_{1}\right]\right) \\
& =f^{u}\left(E\left[S_{2} \mid a_{1}\right]-E\left[S_{2}\right]\right)+f^{e}\left(E\left[S_{2} \mid a_{1}\right]-E\left[E\left[S_{2} \mid e_{1}\right] \mid a_{1}\right]\right) .
\end{aligned}
$$

From (13) and (14),

$$
\begin{aligned}
S_{2} & =E\left[S_{2}\right]+\left(1+\beta_{1}\right)\left(c_{1}-\bar{c}_{1}\right)+\left(1+\beta_{2}\right)\left(a_{1}-\bar{a}_{1}\right)+\delta . \\
E\left[S_{2} \mid a_{1}\right] & =E\left[S_{2}\right]+\left(1+\beta_{1}\right)\left(\frac{C}{V_{a}}\right)\left(a_{1}-\bar{a}_{1}\right)+\left(1+\beta_{2}\right)\left(a_{1}-\bar{a}_{1}\right) \\
& =E\left[S_{2}\right]+\left(a_{1}-\bar{a}_{1}\right)\left[\left(1+\beta_{1}\right)\left(\frac{C}{V_{a}}\right)+\left(1+\beta_{2}\right)\right] .
\end{aligned}
$$

By (18) and multivariate normality,

$$
E\left[E\left[S_{2} \mid e_{1}\right] \mid a_{1}\right]=E\left[S_{2}\right]+\left(a_{1}-\bar{a}_{1}\right)\left(1+\beta_{e_{2} e_{1}}\right)\left(1+\frac{C}{V_{a}}\right) .
$$

It follows that

$$
\begin{aligned}
E\left[S_{2}-S_{1} \mid a_{1}\right]= & \left(a_{1}-\bar{a}_{1}\right)\left\{f^{u}\left[\left(1+\beta_{1}\right)\left(\frac{C}{V_{a}}\right)+\left(1+\beta_{2}\right)\right]\right. \\
& \left.+f^{e}\left[\left(\beta_{1}-\beta_{e_{2} e_{1}}\right)\left(\frac{C}{V_{a}}\right)+\left(\beta_{2}-\beta_{e_{2} e_{1}}\right)\right]\right\}
\end{aligned}
$$

11 Since earnings is the sum of cash flows and accruals, a bivariate regression of future returns on earnings and on accruals is essentially equivalent to a bivariate regression of future returns on earnings and on cash flows. However, the univariate regressions of returns on accruals or on cash flows are not equivalent. 


$$
\begin{aligned}
= & \left(a_{1}-\bar{a}_{1}\right)\left\{f^{u}\left[\left(1+\beta_{1}\right)\left(\frac{C}{V_{a}}\right)+\left(1+\beta_{2}\right)\right]\right. \\
& \left.+f^{e}\left(\beta_{1}-\beta_{2}\right) \frac{C^{2}-V_{a} V_{c}}{V_{a}\left(V_{a}+V_{c}+2 C\right)}\right\} .
\end{aligned}
$$

The second equality follows from Equation (15).

On the right-hand side of the last equality, the first term within the brackets reflects the misvaluations of the fraction $f^{u}$ of investors who ignore earnings entirely. This leads to direct underreaction to the higher date 1 earnings associated with higher date 1 accruals $a_{1}$, and underreaction to the implications of a higher accrual for future earnings. Since these investors ignore the implications of higher accruals and resulting earnings, they underreact. So, if $f^{e}=0$, the future return is increasing with the deviation of accruals from their mean.

The other term reflects the fraction $f^{e}$ of investors who attend to earnings but not to how earnings is divided between accruals and cash flows. The expected error made by these investors given current-period accruals is the difference between the correct forecast given current-period accruals, and the forecast of future earnings based on the effect of current-period accruals on current-period earnings. If $\left|\operatorname{corr}\left(a_{1}, c_{1}\right)\right| \neq 1$, the $f^{e}$ term in (28) is negative, since $\beta_{1}>\beta_{2}$ and $C^{2}-V_{a} V_{c}=V_{a} V_{c}\left(\operatorname{corr}^{2}\left(a_{1}, c_{1}\right)-1\right)<0$.

The model is symmetric with respect to $c_{1}$ and $a_{1}$, except for the assumption that $\beta_{1}>\beta_{2}$ in (11). Thus, replacing $a_{1}$ with $c_{1}, c_{1}$ with $a_{1}, \beta_{2}$ with $\beta_{1}$, and $\beta_{1}$ with $\beta_{2}$ in (28), we obtain the expected return conditional on the date 1 cash flow,

$$
\begin{aligned}
E\left[S_{2}-S_{1} \mid c_{1}\right]= & \left(c_{1}-\bar{c}_{1}\right)\left\{f^{u}\left[\left(1+\beta_{1}\right)+\left(1+\beta_{2}\right)\left(\frac{C}{V_{c}}\right)\right]\right. \\
& \left.+f^{e}\left(\beta_{1}-\beta_{2}\right) \frac{-C^{2}+V_{a} V_{c}}{V_{c}\left(V_{a}+V_{c}+2 C\right)}\right\} .
\end{aligned}
$$

The $f^{e}$ term in (29) contributes to underreaction to cash flow since $\beta_{1}>\beta_{2}$ and $-C^{2}+V_{a} V_{c} \geqslant 0$. The $f^{u}$ term also contributes to underreaction to cash flow, since

$$
\left(1+\beta_{1}\right) V_{c}+\left(1+\beta_{2}\right) C>\left(1+\beta_{2}\right)\left(V_{c}+C\right)>0,
$$

where the first inequality follows from $\beta_{1}>\beta_{2}$ and the second from (16). Therefore, overall there is underreaction to cash flow.

The above analysis is summarized in Proposition 2.

Proposition 2. Suppose that, at date 1, fraction $f^{u}$ of investors do not attend to any of earnings $e_{1}$, cash flow $c_{1}$, or accruals $a_{1}$; that fraction $f^{e}$ attends to earnings but not to its decomposition between cash flow and accruals; and that 
the remaining fraction $f^{a}=1-f^{u}-f^{e}$ attends to all publicly available information. Then:

1. A firm with date 1 cash flows that are above (below) their unconditional mean is undervalued (overvalued), and subsequently on average earns positive (negative) abnormal returns.

2. If $f^{u}$ is sufficiently small relative to $f^{e}$, a firm with date 1 accruals that are above (below) their unconditional mean is overvalued (undervalued) and subsequently on average earns negative (positive) abnormal returns.

Part 1 indicates that, under our assumption that cash flow is a more favorable incremental predictor of future earnings than is accruals $\left(\beta_{1}>\beta_{2}\right.$ in Equation (11)), there is an underreaction to cash flow. As discussed after footnote 8 , this assumption is equivalent to the assumption that, after controlling for current-period earnings, accruals are a negative incremental predictor of future earnings.

Part 2 indicates that, if enough attention is paid to earnings, there is overreaction to the accruals component of earnings. One case in which the condition for Part 2 of Proposition 2 applies is $f^{u}=0$ (all investors attend to earnings). The ability of accruals to forecast returns in this case reflects the fact, as discussed at the end of Subsection 2.1, that $\beta_{1}>\beta_{e_{2} e_{1}}>\beta_{2}$. In other words, high current-period cash flow is a more favorable forecaster of future earnings than is high current-period earnings, which is a more favorable forecaster than high current-period accruals. Those investors who focus on earnings without attention to its components do not take into account that, for a given level of earnings, the true expectation of future earnings is higher when cash flow is high than when it is low. Therefore, such investors undervalue firms with high cash flow and overvalue firms with low cash flow. Such misvaluation is subsequently corrected, causing abnormal returns.

Similarly, those investors who focus on earnings without attending to its components do not take into account that, for a given level of earnings, the true expectation of future earnings is higher when accruals are low than when they are high. Therefore, such investors overvalue firms with high accruals and undervalue firms with low accruals, leading to subsequent abnormal returns.

When $f^{u}>0$, so that some investors neglect earnings, there is general underreaction to earnings. Since cash flow is a more favorable predictor of earnings than accruals, $f^{u}>0$ further implies underreaction to cash flow relative to accruals. This reinforces the underreaction to cash flows, which provides the intuition for the cash flow anomaly asserted in Part 1. Even though investors overreact to accruals relative to cash flow, if $f^{u}$ is sufficiently large relative to $f^{e}$, there is underreaction even to the accruals component of earnings. This explains why the Part 2 conclusion in Proposition 2 that high accruals are associated with low returns requires that the fraction of investors who attend only to 
earnings (and not its components) be sufficiently large relative to the fraction of investors who neglect earnings entirely.

Thus, the analysis is consistent with the accrual anomaly, but the condition under which it applies is different from that proposed by Sloan (1996), that accruals be a less favorable predictor than cash flows of future earnings $\left(\beta_{1}>\beta_{2}\right)$. Here, $\beta_{1}>\beta_{2}$ is a necessary but not sufficient condition for the accrual anomaly to apply. Thus, an empirical implication of Proposition 2 is that the accrual anomaly can vanish or even reverse for sets of firms for which cash flow is a more positive predictor than accruals of future earnings, if the difference $\beta_{1}-\beta_{2}$ is not too large and/or $f^{e}$ is not sufficiently large compared to $f^{u}$. A further empirical implication is that the positive relation of cash flows to subsequent returns should be more robust across different firms, trading venues, and time periods than the negative relation of accruals to subsequent returns. Specifically, the accrual anomaly could reverse for firms that have greater neglect of earnings (higher $f^{u}$ ). Consistent with this implication, Pincus, Rajgopal, and Venkatachalam (2007) find that the cash flow anomaly is reliably present in a much wider set of countries (12 out of 20) than the accrual anomaly (3, including the United States).

Proposition 1 indicates that a proxy for $f^{u}$ that can be used for further empirical testing is the strength of the firm's post-earnings announcement drift. Alternatively, other proxies for the sensitivity of a firm's misvaluation to its earnings surprises could be used based upon contemporaneous misvaluation proxies. Either type of proxy for $f^{u}$ can be used to test Part 2 of Proposition 2 as well.

\subsection{The relative strength of accruals and cash-flow-based return predictability}

Our analysis provides insight regarding the strength of the cash flow and accruals anomalies. Let $b_{a}$ be the slope coefficient in the relation between accruals surprises $a_{1}-\bar{a}_{1}$ and subsequent abnormal stock returns, and let $b_{c}$ be the slope coefficient in the relation between cash flow surprises $c_{1}-\bar{c}_{1}$ and subsequent abnormal stock returns. Then, by Equations (28) and (29),

$$
\begin{aligned}
& b_{a}=f^{u}\left[\left(1+\beta_{1}\right)\left(\frac{C}{V_{a}}\right)+\left(1+\beta_{2}\right)\right]+f^{e}\left(\beta_{1}-\beta_{2}\right) \frac{C^{2}-V_{a} V_{c}}{V_{a}\left(V_{a}+V_{c}+2 C\right)} \\
& b_{c}=f^{u}\left[\left(1+\beta_{1}\right)+\left(1+\beta_{2}\right)\left(\frac{C}{V_{c}}\right)\right]+f^{e}\left(\beta_{1}-\beta_{2}\right) \frac{-C^{2}+V_{a} V_{c}}{V_{c}\left(V_{a}+V_{c}+2 C\right)} .
\end{aligned}
$$

\subsubsection{Effects of variations in attention on the accruals and cash flow} anomalies. Since the $f^{u}$ terms are positive in both cash flow and accruals equations in (31), while the $f^{e}$ term is positive in the cash flow equation and negative in the accruals equation, we have: 


\section{Proposition 3.}

1. The strength of the relation between cash flow and subsequent abnormal returns, $b_{c}$, is increasing in $f^{u}$ and $f^{e}$.

2. If there is an accrual anomaly $\left(b_{a}<0\right)$, the strength of the relation between accruals and subsequent abnormal returns, $\left|b_{a}\right|=-b_{a}$, is decreasing in $f^{u}$ and increasing in $f^{e}$.

3. A shift in investor probability mass from attending only to earnings to neglecting both earnings and its components (increasing $f^{u}$ and decreasing $f^{e}$ by the same amount) intensifies the cash flow anomaly.

Part 1 in Proposition 3 reflects the fact that neglect of earnings and neglect of earning components both reinforce the cash flow anomaly. A shift in investor probability mass from attending to both earnings and its components to either neglecting earnings components (increasing $f^{e}$ ) or neglecting earnings as well as its components (increasing $f^{u}$ ) intensifies the cash flow anomaly. An untested empirical implication of Part 1 is that the cash flow anomaly will be stronger when attention declines. Proxies for attention or inattention from the literature, such as trading volume, the number of distracting news events, and Friday announcements, could be used to test this implication.

Intuitively, if the fraction of investors that attend to earnings but neglect accruals and cash flow, $f^{e}$, increases (at the expense of fully attentive investors), then this neglect favors underreaction to cash flows and overreaction to accruals. Empirically, the complexity or length of the firm's annual report is a proxy for the incremental cost of attending to earnings components (where the earnings level itself can be attended to without delving into these details). It is therefore a possible proxy for variation in $f^{e}$, holding $f^{u}$ constant. If the fraction of investors that neglect earnings, $f^{u}$, increases, the underreaction to cash flows is reinforced, whereas the overreaction to accruals is weakened. As mentioned in the discussion following Proposition 2, the strength of post-earnings announcement drift can be used as an empirical proxy for $f^{u}$ for a stock or set of stocks.

Another attention proxy is the share ownership of institutional versus individual investors. If institutional investors are attentive to accruals, cash flows, and earnings, then high institutional ownership and low individual ownership should be associated with low $f^{u}$ (neglect of both earnings and accruals) and $f^{e}$ (neglect of earnings). Low $f^{u}$ and low $f^{e}$ both weaken the cash flow anomaly. Furthermore, if institutional ownership is high enough to drive both $f^{u}$ and $f^{e}$ toward zero (so that few investors neglect the split of earnings between cash flow and accruals), the accrual anomaly should become arbitrarily weak. Empirically, Collins, Gong, and Hribar (2003) find that the accrual anomaly is stronger in stocks with lower ownership by active institutional investors. 
With regard to Part 3, a shift in investor probability mass from attending only to earnings to neglecting earnings as well has two opposing effects on the cash flow anomaly, since both $f^{e}$ and $f^{u}$ terms contribute to underreaction to cash flow. However, decreasing $f^{e}$ and increasing $f^{u}$ by the same amount $\Delta$ increases $b_{c}$ by

$$
\Delta \frac{\left(V_{c}+C\right)\left[\beta_{1}\left(V_{c}+C\right)+\beta_{2}\left(V_{a}+C\right)+\left(V_{a}+V_{c}+2 C\right)\right]}{V_{c}\left(V_{a}+V_{c}+2 C\right)}>0 .
$$

When cash flow is high, for example, investors who attend only to earnings (fraction $f^{e}$ ) neglect the cash flow but draw a somewhat positive inference from the (on average) high earnings. However, investors who do not attend to earnings (fraction $f^{u}$ ) do not draw any inference from the cash flow or the earnings. Therefore, decreasing $f^{e}$ and increasing $f^{u}$ by the same amount strengthens the cash flow anomaly.

2.4.2 Effects of earnings quality on accrual and cash flow anomalies. It has often been alleged that earnings management reduces the quality of earnings, in the sense that earnings are a less accurate indicator of long-run firm performance. In our setting, such a reduction in earnings quality associated with accruals would be reflected in a low $\beta_{2}$ in Equation (11), so that currentperiod level of accruals becomes a much less favorable predictor of future earnings than current-period cash flow.

We now consider the implications of lower earnings quality in this sense for the strengths of the accrual and cash flow anomalies. Differentiating $b_{a}$ in (31) with respect to $\beta_{2}$ yields

$$
\frac{\partial b_{a}}{\partial \beta_{2}}=f^{u}+f^{e}\left[\frac{V_{a} V_{c}-C^{2}}{V_{a}\left(V_{a}+V_{c}+2 C\right)}\right]>0,
$$

where the final inequality holds because $V_{a} V_{c} \geqslant C^{2}$. This derivative indicates that if there is an accrual anomaly $\left(b_{a}<0\right)$, then when earnings quality increases (accruals become a more favorable incremental predictor of future earnings), the accrual anomaly becomes weaker (the negative coefficient increases, moving it closer to zero). If there is no accrual anomaly or a reverse accruals effect $\left(b_{a} \geqslant 0\right)$, then the effect becomes even more reversed.

Differentiating $b_{c}$ in (31) with respect to $\beta_{2}$ yields

$$
\frac{\partial b_{c}}{\partial \beta_{2}}=f^{u}\left(\frac{C}{V_{c}}\right)+f^{e}\left[\frac{C^{2}-V_{a} V_{c}}{V_{c}\left(V_{a}+V_{c}+2 C\right)}\right] \text {. }
$$

Since $C^{2} \leqslant V_{a} V_{c}$, the above equation indicates that the cash flow anomaly is weakened by an increase in earnings quality if $C<0$. 
Proposition 4. Consider an increase in accruals quality that increases $\beta_{2}$, i.e., makes the incremental forecasting power of current-period accruals for future earnings closer to that of current-period cash flows. Then, an increase in earnings quality:

1. Weakens the accrual anomaly; and

2. Weakens the cash flow anomaly if the covariance of accruals with cash flows is negative.

The $\beta_{2}$ parameter can be estimated by running the regression in (11). Therefore, the prediction about the relation of accruals quality to the accrual anomaly is empirically testable.

Intuitively, in Part 1 of Proposition 4, the accrual anomaly is driven by the low quality of the accruals component of earnings, so if this component becomes a more favorable forecaster of earnings, a strong investor reaction to accruals becomes a less severe mistake. This is reinforced by a subtler effect. When earnings quality increases owing to an increase in $\beta_{2}$, the persistence of earnings, $\beta_{e_{2} e_{1}}$, increases (see Equation (15)). Investor neglect of the implications of current-period earnings for future earnings (as reflected in $f^{u}$ ) therefore causes greater underreaction to earnings as the persistence of earnings increases (Proposition 1, Part 3). This greater general underreaction further weakens the overreaction to accruals.

In Part 2, the intuition for the effect of a change in accruals quality on the cash flow anomaly reflects the same two effects. On the one hand, higher accruals quality eases the misperceptions associated with the neglect of accruals and cash flow information. This is reflect in the negative $f^{e}$ term in (34), indicating a weakening of the cash flow anomaly.

More subtly, if cash flow covaries negatively with accruals, higher cash flow on average implies lower accruals, and lower accruals on average imply lower current earnings, $e_{1}$, as well as lower total firm value, $e_{1}+e_{2}$. This is in the opposite direction of the direct effect of cash flow on firm value. An increase in $\beta_{2}$ strengthens the association between accruals and firm value, $e_{1}+e_{2}$. Therefore, given neglect of current earnings, it further weakens underreaction to cash flow. Past empirical evidence (e.g., Sloan 1996) shows that the covariance between cash flow and accruals is negative. Thus, Part 2 of Proposition 4 predicts that an increase in earnings quality weakens the cash flow anomaly.

Testing of Proposition 4 requires controlling for other exogenous parameters, such as the variances of accruals and cash flows. This is important, for example, in evaluating differences in earnings quality that derive from differing earnings management practices, since a firm that manages earnings heavily may have greater variability in accruals. We next examine the effects on anomalies of varying volatilities and correlations as well. 


\subsubsection{Effects of accrual and cash flow volatilities and correlations on} accruals and cash flow anomalies. The $f^{e}$ term, which reflects investor inattention to the division of earnings between cash flow and accruals, is the sole source of mispricing when $f^{u}=0$. We define $b_{a}^{0}$ and $b_{c}^{0}$ as the values of the slope coefficients that come from neglect of earnings components, not from neglect of earnings itself (i.e., the $f^{u}$ term),

$$
\begin{aligned}
& b_{a}^{0}=f^{e}\left(\beta_{1}-\beta_{2}\right)\left[\frac{C^{2}-V_{a} V_{c}}{V_{a}\left(V_{a}+V_{c}+2 C\right)}\right] \\
& b_{c}^{0}=f^{e}\left(\beta_{1}-\beta_{2}\right)\left[\frac{-C^{2}+V_{a} V_{c}}{V_{c}\left(V_{a}+V_{c}+2 C\right)}\right] .
\end{aligned}
$$

It follows that the relative size of the slope coefficients in the accruals regression and in the cash flow regression is determined by the ratio of the variances of accruals and of cash flows:

$$
\left|\frac{b_{a}^{0}}{b_{c}^{0}}\right|=-\frac{b_{a}^{0}}{b_{c}^{0}}=\frac{V_{c}}{V_{a}} .
$$

For example, if $f^{u}=0$ and $V_{c}=V_{a}$, then $b_{a}^{0}=-b_{c}^{0}$, so that the accruals and cash flow anomalies are equally strong.

So far in this discussion we have assumed that $f^{u}=0$, which eliminates post-earnings announcement drift by Proposition 1. More generally, when $f^{u}>0$ in (31), the slope coefficients $b_{a}$ and $b_{c}$ are larger than the corresponding $b_{a}^{0}$ and $b_{c}^{0}$. Since $b_{c}^{0}>0$, it follows that, if $f^{u}>0$ and there is an accrual anomaly $\left(b_{a}<0\right)$,

$$
\begin{aligned}
-\frac{b_{a}}{b_{c}} & =\frac{-f^{u}\left[\left(1+\beta_{1}\right)\left(\frac{C}{V_{a}}\right)+\left(1+\beta_{2}\right)\right]-b_{a}^{0}}{f^{u}\left[\left(1+\beta_{1}\right)+\left(1+\beta_{2}\right)\left(\frac{C}{V_{c}}\right)\right]+b_{c}^{0}} \\
& <-\frac{b_{a}^{0}}{f^{u}\left[\left(1+\beta_{1}\right)+\left(1+\beta_{2}\right)\left(\frac{C}{V_{c}}\right)\right]+b_{c}^{0}} \\
& <-\frac{b_{a}^{0}}{b_{c}^{0}}=\frac{V_{c}}{V_{a}}
\end{aligned}
$$

where the first inequality follows from (17) and the second from (30). Thus, the relative strength of the cash flow effect is greater than what is implied by the variance ratio. For example, if cash flow and accruals are equally variable, then (36) indicates an equally strong cash flow and accrual effect. But, if some investors ignore earnings, so that $f^{u}>0$, by (37) the cash flow effect is stronger than the accruals effect. Thus, although the empirical literature has focused 
more on accruals than cash flow, our analysis predicts that the cash flow effect can be stronger.

This analysis is summarized in Proposition 5.

\section{Proposition 5.}

1. If investors always attend to earnings, so that $f^{u}=0$, then the ratio of the absolute slopes in the univariate regressions of subsequent returns on accruals and on cash flows, $-b_{a}^{0} / b_{c}^{0}$, is equal to the ratio of the variance of cash flow to the variance of accruals, $V_{c} / V_{a}$.

2. If some investors neglect earnings, so that $f^{u}>0$, and if there is an accrual anomaly $\left(b_{a}<0\right)$, then the ratio of the absolute slopes in the univariate regressions of subsequent returns on accruals and on cash flows, $-b_{a} / b_{c}$, is less than the ratio of the variance of cash flow to the variance of accruals, $V_{c} / V_{a}$.

Intuitively, consider an investor who focuses on current-period earnings in forecasting future earnings. For simplicity, suppose that the covariance of current-period accruals and current-period cash flow is zero. High accruals increase current-period earnings, making the investor more optimistic about future earnings. The investor on average becomes too optimistic, because he forecasts high future cash flow based on the unconditional relation between current-period earnings and future earnings. Thus, the investor's overoptimism will be greater to the extent that an extra unit of earnings is, on average, associated with higher future earnings more strongly than is an extra unit of accruals.

When accruals are highly variable relative to cash flow, most variation in earnings comes from variations in accruals. In this case, the forecasts of investors with limited attention who condition on earnings are almost equivalent to fully attentive forecasts based on accruals. High accruals bring about little overoptimism, so the slope $b_{a}^{0}$ approaches zero. In contrast, when the variance of accruals is low relative to the variance of cash flow, the forecasts of investors with limited attention who condition on a given deviation of earnings from mean earnings are similar to the forecasts that would be made based on a comparable deviation of cash flow from its mean. If in fact it is the level of accruals, not cash flow, that is high, then this misattribution brings about a great deal of overoptimism.

A higher value of $b_{a}$ means that it is less negative, a weaker accruals effect. So, Part 2 of Proposition 5 indicates that the cash flow effect can be stronger than the accruals effect even if the relative variability is equal.

One reason why a firm's accruals might be highly variable is if it engages in extensive earnings management. If so, then accruals may be a less favorable predictor of future earnings (lower $\beta_{2}$ ). It is therefore striking that the prediction of Proposition 5 is independent of the forecasting powers of cash flow or 
accruals, $\beta_{1}$ or $\beta_{2}$, for future earnings. ${ }^{12}$ The independence of the prediction of Proposition 5 from $\beta_{1}$ and $\beta_{2}$ simplifies empirical testing.

By Proposition 5, a higher variance of accruals relative to cash flow implies a weaker accruals effect. With regard to Part 1, if the accruals or cash flow effects are empirically evaluated using hedge profits based upon fractile sorts, the spread in the independent variables is affected by their variances. Under normality, among a set of ex ante identical firms, a higher variance of accruals implies a higher mean high-low fractile spread in accruals. Since the relative weakness in the slope is proportional to the relative variances, whereas the fractile spread increases only as the square root of the variances, there is partial cancellation. Overall, Proposition 5 indicates that for fractile spreads, among a set of ex ante identical firms that obtain different realizations of accruals and cash flows, the ratio of the hedge profits based upon accruals versus those based upon cash flow will be inversely proportional to the ratio of the standard deviations (instead of variances) of accruals and of cash flows.

In the online Technical Appendix, we develop additional implications of the model for the effects of the correlation between cash flow and accruals on the separate slope coefficients. One implication is that if investors are fully attentive to earnings, but some do not attend to accruals and cash flow separately, then the slope coefficient $b_{a}^{o}$ is increasing, and the slope coefficient $b_{c}^{o}$ is decreasing, with correlation $\rho$. So, greater correlation weakens both the accrual and cash flow anomalies. Intuitively, both accrual and cash flow effects derive from investors neglecting the differing implications for long-run earnings of current-period cash flow versus accruals. When accruals and cash flow are highly correlated, each is also highly correlated with earnings, so that ignoring the distinction between different earnings components is, on average, of little consequence.

If $f^{u}>0$, so that some investors neglect earnings, not just its components, another implication is that higher $\rho$ further weakens the accruals effect (increases the negative slope $b_{a}$ ). Intuitively, when the correlation between accruals and cash flow is higher, high accruals tend to be more positively (or less negatively) associated with high cash flow. Since the market underreacts to earnings $\left(f^{u}>0\right)$, this effect promotes underreaction to the higher accruals, which tends to oppose the pure accruals effect.

\subsection{The profit anomaly and post-earnings announcement drift}

Balakrishnan, Bartov, and Faurel (2010) provide evidence that the level of (as distinguished from the surprise in) earnings predicts future stock returns, and that this effect is not subsumed by post-earnings announcement drift. There

12 Intuitively, the prediction in (36) is about the relative sizes of these anomalies. If $\beta_{2} \ll \beta_{1}$, so that the neglect of accruals makes a big difference for value, the accrual anomaly will be stronger (as indicated by Equation (33) in the derivation of Proposition 4). However, in such a case the cash flow anomaly also tends to be stronger (as indicated by the $f^{e}$ term in Equation (34)). 
is also evidence that stocks with high earnings, on average, earn higher returns (Chen, Novy-Marx, and Zhang 2010). In this subsection, we show that investor inattention can explain the profit anomaly, the return predictability based on the level of earnings, and that, consistent with existing evidence, the effect is incremental to the post-earnings announcement drift.

To illustrate the key intuition, we simplify the model by assuming that there are only two types of investors: those who attend to earnings alone and those who do not. In other words, we set the fraction who attend to earnings components, $f^{a}$, to zero. We focus here on the issue of return predictability based upon earnings or on earnings surprises, not on earnings components. At some point prior to the date 1 earnings announcement, both groups of investors form their expectations $f_{0}$ of the upcoming earnings $e_{1}$ based on available date 0 information. We can view $f_{0}$ as either an analyst forecast, or the previous level of earnings. After the date 1 earnings announcement, a fraction $\lambda$ of investors are inattentive and stick to their original beliefs, and a fraction $1-\lambda$ of investors use earnings information to update their beliefs. Here, $\lambda=f^{u}$ from before; we rename it here to avoid confusion with our terminology for the analyst forecast, $f_{0}$.

As before, we assume that the date 2 stock value is the sum of the date 1 earnings $e_{1}$ and the date 2 earnings $e_{2}$,

$$
S_{2}=e_{1}+e_{2}
$$

where

$$
e_{2}=\bar{e}_{2}+\beta_{e}\left(e_{1}-\bar{e}_{1}\right)+\delta_{e} .
$$

The date 1 earnings can be decomposed into the forecast $f_{0}$ and additional information $\varepsilon$,

$$
e_{1}=f_{0}+\varepsilon,
$$

where $f_{0} \sim N\left(\bar{f}_{0}, V_{f}\right)$ and $\operatorname{cov}\left(f_{0}, \varepsilon\right)=0$. We assume that forecasts are, on average, unbiased $\left(\bar{e}_{1}=\bar{f}_{0}\right) .{ }^{13}$ Date 0 earnings forecasts of $e_{1}$ are made prior to the arrival of $e_{1}$, so we assume that they are less informative than $e_{1}$ itself about date 2 earnings. So, comparing $\beta_{f}$ in the predictive regression,

$$
e_{2}=\bar{e}_{2}+\beta_{f}\left(f_{0}-\bar{f}_{0}\right)+\delta_{f},
$$

with $\beta_{e}$ in Equation (39), it follows that $\beta_{e}>\beta_{f} \geqslant 0$. Furthermore, the dominance of $e_{1}$ over $f_{0}$ as a predictor of future earnings implies that a bivariate regression of $e_{2}$ on $e_{1}$ and $f_{0}$ reduces to a univariate regression on $e_{1}$. So, the expectations of attentive and inattentive investors are

$$
\begin{aligned}
E\left[S_{2} \mid e_{1}, f_{0}\right]= & E\left[S_{2} \mid e_{1}\right]=E\left[S_{2}\right]+\left(1+\beta_{e}\right)\left(e_{1}-\bar{e}_{1}\right) \\
& E\left[S_{2} \mid f_{0}\right]=E\left[S_{2}\right]+\left(1+\beta_{f}\right)\left(f_{0}-\bar{f}_{0}\right) .
\end{aligned}
$$

\footnotetext{
13 In reality, analyst forecasts are biased, but unbiasedness is a simple benchmark and is not crucial for our results.
} 
As before (see (10)), the date 1 stock price is a weighted average of the beliefs of attentive and inattentive investors. Recalling that $\lambda$ denotes the fraction of investors who do not attend to earnings, the date 1 stock price can be written as

$$
S_{1}=E\left[S_{2}\right]+(1-\lambda)\left(1+\beta_{e}\right)\left(e_{1}-\bar{e}_{1}\right)+\lambda\left(1+\beta_{f}\right)\left(f_{0}-\bar{f}_{0}\right)-A \operatorname{var}\left(S_{2}\right) x_{0},
$$

and the change in stock price is

$$
S_{2}-S_{1}=\lambda\left(1+\beta_{e}\right)\left(e_{1}-\bar{e}_{1}\right)-\lambda\left(1+\beta_{f}\right)\left(f_{0}-\bar{f}_{0}\right)+A \operatorname{var}\left(S_{2}\right) x_{0}+\delta_{e} .
$$

In this setting, it is not hard to derive the profit anomaly, the finding that the level of earnings is a positive predictor of future returns. However, given the well-known finding of post-earnings announcement drift, it is more interesting to derive that profit is a predictor of future returns even after controlling for the earnings surprise. We therefore run a "horse race" between the profit anomaly and post-earnings announcement drift by regressing the stock price change on both the level of date 1 earnings $e_{1}$, and the earnings surprise $e_{1}-f_{0}$ :

$$
S_{2}-S_{1}=b_{0}+b_{1} e_{1}+b_{2}\left(e_{1}-f_{0}\right)+\epsilon .
$$

The coefficient on the level of earnings, $b_{1}$, captures the profit anomaly, and the coefficient on the earnings surprise, $b_{2}$, captures post-earnings announcement drift. The regression coefficients $b_{1}$ and $b_{2}$ are

$$
\begin{aligned}
& b_{1}=\lambda\left(\beta_{e}-\beta_{f}\right) \\
& b_{2}=\lambda\left(1+\beta_{f}\right) .
\end{aligned}
$$

Since $\beta_{e}>\beta_{f} \geqslant 0, b_{1}>0$ and $b_{2}>0$. Therefore, there are both a profit anomaly and post-earnings announcement drift, and neither subsumes the other.

The results imply that both anomalies stem from investor inattention to earnings information $(\lambda)$. The effect of attention toward earnings news can be viewed as containing two parts. First is a shift in the mean belief about the current level of earnings $e_{1}$ by the amount of the surprise $\left(\varepsilon=e_{1}-f_{0}\right)$. Second is greater certainty about the current level of earnings ( $e_{1}$ for sure instead of $f_{0}$ on average), which causes the use of a different coefficient when investors forecast future earnings based on the information they have (use of $\beta_{e}$ instead of $\beta_{f}$ ). When there is inattention, the mean shift causes a misperception (and subsequent return predictability) induced by the earnings surprise, i.e., postearnings announcement drift. The second effect, a failure to update sufficiently strongly for any given level of date 1 expected earnings, induces mispricing in relation to the level of earnings. ${ }^{14}$ Therefore, the earnings level predicts returns (the profit anomaly) even after controlling for the earnings surprise.

14 Holding earnings surprise $\varepsilon$ constant, a unit increase in earnings level $\left(e_{1}=f_{0}+\varepsilon\right)$ is equivalent to a unit increase in $f_{0}$. This increase in earnings level increases the expected stock price by $1+\beta f$ for inattentive investors, which is smaller than the increase in the expectation of attentive investors, $1+\beta_{e}$. So, there is underreaction to variations in the earnings level above and beyond the underreaction to the earnings surprise. 
A further untested empirical implication is that the profit anomaly is stronger when the current level of earnings is a much better predictor of future earnings than are prior earnings expectations such as analyst forecasts and prior earnings (higher $\beta_{e}-\beta_{f}$ ). The following proposition summarizes these results:

\section{Proposition 6.}

1. If fraction $\lambda>0$ of investors ignore the information in current-period earnings and hold on to their beliefs based on prior earnings expectations, both the level of earnings and earnings surprise (earnings minus prior earnings expectations) predict future stock returns.

2. There is a stronger profit anomaly when current earnings is a much better predictor of future earnings than prior earnings expectations.

\section{Trading Profits and Equilibrium Inattention}

It could be argued that inattentive investors should withdraw from the market instead of trading; and that if they do trade, they will on average lose money, and in the long run, tend to vanish. However, in standard models of securities markets, individuals do find it optimal to trade despite having informational disadvantages relative to some subsets of other traders. Furthermore, attending to more information is costly, so those who devote more cognitive resources to an information signal (such as a given firm's earnings, accruals, or cash flow) need not do better overall. Attending to a given signal allows individuals to value the firm more accurately, at the cost of withdrawing attentional resources from some other activity. For example, attention demands time, which has a monetary opportunity cost. Since there is both a benefit and a cost to attending to a given public signal, in a long-run equilibrium in which wealths of investors shift over time, it does not follow that fully attentive investors dominate.

In this section, we show that if attention is costly, there can be an equilibrium in which inattentive investors find it optimal to trade; and in which inattentive and attentive investors on average achieve the same expected utility, and therefore coexist. We first show that investors who do not attend to all publicly available information can nevertheless earn positive expected trading profits. Next, when individuals decide to attend by balancing the cost of attending against the expected utility benefits from making better-informed decisions, we show that there can exist an equilibrium where a positive fraction of investors decide not to attend to some public information. Since the attentive and inattentive achieve equal ex ante welfare, there is no reason to expect the inattentive to vanish in the long run.

\subsection{Expected trading profits}

Investors who neglect the information contained in earnings or its components make inferior trades, which raises the question of whether such behavior can 
survive in equilibrium. We now show that inattentive investors can still earn positive expected profits owing to noise trading. We consider investors who make rational plans when they allocate attention ex ante, foreseeing the fact that if they choose not to attend to an information item then their subsequent beliefs will be biased. We first calculate the true expected trading profits to investors as a function of whether they attend to information signals.

Using the formula for the optimal security position given by (4), the expected profit of an investor who ignores earnings and its components in forming expectations is

$$
E\left[x^{u}\left(S_{2}-S_{1}\right)\right]=E\left[\frac{E\left[S_{2}\right]-S_{1}}{\operatorname{Avar}\left(S_{2}\right)}\left(S_{2}-S_{1}\right)\right] .
$$

For an investor who attends to earnings information only, her expected profit is

$$
E\left[x^{e}\left(S_{2}-S_{1}\right)\right]=E\left[\frac{E\left[S_{2} \mid e_{1}\right]-S_{1}}{\operatorname{Avar}\left(S_{2}\right)}\left(S_{2}-S_{1}\right)\right] .
$$

Computing the expected profits of inattentive investors in Equations (47) and (48), we have the following proposition:

Proposition 7. When there is a large amount of noise trading ( $V_{x}$ sufficiently large), inattentive investors earn positive expected profits.

The proof is in the Appendix. We find that uninformed investors (those who ignore earnings) can earn positive expected profits owing to noise trading. Both noise trading and the presence of uninformed investors positively contribute to the expected trading profits of investors who attend to earnings but ignore its components.

\subsection{Expected utility and characterization of equilibrium}

We now evaluate the expected utility of each type of investor. Given the meanvariance utility function in Equation (1), the consumption (2), and the demand for the risky security in Equation (4), the expected utility of investor group $i$ is as follows:

$$
E\left[U^{i}\left(C_{2}\right)\right]=E\left[\left(W-k^{i}\right)+\frac{\left(E^{i}\left[S_{2}\right]-S_{1}\right)^{2}}{2 A \operatorname{var}\left(S_{2}\right)}\right] .
$$

Assume that the cost $k^{i}$ of attention is equal to zero for uninformed investors $\left(k^{u}=0\right)$ and that the cost of attending to earnings only is less than that of attending to cash flow and accruals separately $\left(k^{e}<k^{a}\right)$.

From multivariate normality, $E^{i}\left[S_{2}\right]-S_{1}$ is normally distributed with mean zero since $E\left[S_{1}\right]=E\left[S_{2}\right]=E\left[E^{i}\left[S_{2}\right]\right]$. Thus, $\left(E^{i}\left[S_{2}\right]-S_{1}\right)^{2}$ follows a 
chi-square distribution. Therefore, the expected utility of each group of investors is

$$
\begin{aligned}
& E\left[U^{u}\left(C_{2}\right)\right]=W+\frac{\operatorname{var}\left(S_{1}\right)}{2 A \operatorname{var}\left(S_{2}\right)} \\
& E\left[U^{e}\left(C_{2}\right)\right]=W-k^{e}+\frac{\operatorname{var}\left(E\left[S_{2} \mid e_{1}\right]-S_{1}\right)}{2 A \operatorname{var}\left(S_{2}\right)} \\
& E\left[U^{a}\left(C_{2}\right)\right]=W-k^{a}+\frac{\operatorname{var}\left(E\left[S_{2} \mid c_{1}, a_{1}\right]-S_{1}\right)}{2 A \operatorname{var}\left(S_{2}\right)} .
\end{aligned}
$$

In an equilibrium where the fraction of investors in each category is nonzero, the ability of investors to pay to enter higher-attention categories will cause expected utility to be equated across all three categories:

$$
\frac{\operatorname{var}\left(S_{1}\right)}{2 A \operatorname{var}\left(S_{2}\right)}=-k^{e}+\frac{\operatorname{var}\left(E\left[S_{2} \mid e_{1}\right]-S_{1}\right)}{2 A \operatorname{var}\left(S_{2}\right)}=-k^{a}+\frac{\operatorname{var}\left(E\left[S_{2} \mid c_{1}, a_{1}\right]-S_{1}\right)}{2 \operatorname{Avar}\left(S_{2}\right)} \text {. }
$$

A numerical example of such an equilibrium is provided by the case $V_{c}=$ $V_{a}=V_{\delta}=V_{x}=1, A=1, \operatorname{cov}\left(a_{1}, c_{1}\right)=-0.4, \beta_{1}=0.5, \beta_{2}=0.3$, $f^{u}=0.6, f^{e}=f^{a}=0.2, k^{e}=0.0696$, and $k^{a}=0.0721$. Proposition 8 summarizes the results:

Proposition 8. When attention is costly and is allocated endogenously, under some parameter values there are equilibrium fractions of investors who choose to neglect earnings and its components, and earn the same expected utility as fully attentive investors.

Intuitively, owing to the cost of attention as reflected in $k^{i}$, investors who allocate greater or lesser attention to earnings or its components can coexist in the long run since more attentive investors incur higher opportunity costs of attention. These opportunity costs can be viewed as the benefit from allocating cognitive resources to other decision domains, such as personal life or other investment categories. Previous research that studies the optimization decision for allocating attention (Gabaix and Laibson 2005; Peng 2005; Hirshleifer, Lim, and Teoh 2008; Iliev and Welch 2010) has identified the importance of such opportunity costs of allocating attention to any given domain. Proposition 8 shows that, owing to the trade-off between making wellinformed decisions based upon earnings information versus in other domains (as reflected in the cost of attention function), a lack of attention to earnings can persist in the long run.

\section{Do Investors Fully Compensate for Limited Attention?}

When faced with many relevant signals, investors can try to leverage their attention by focusing on more important information items. However, it is hard 
to identify the most important signal without processing all of them, so such a strategy is necessarily imperfect.

A key assumption of our model is that individuals with limited attention trade based upon their beliefs, and are therefore part of the price-setting process. However, an individual who understands that he is neglecting a relevant public information item in forming his beliefs is free to retreat into autarky, thereby deferring completely to the market price. This raises the question of why an investor would both neglect information yet take a nonzero trading position.

On both psychological and economic grounds, we do not expect that individuals with limited attention would or even should always withdraw into passivity. Evidence from both psychology and market behavior indicates that individuals often fail to adjust appropriately for the fact that they have left some information unprocessed.

Such double neglect makes sense when processing power is limited. Attention and mental processing are needed to adjust for the fact that information items that are not being attended to in detail may affect the reliability of the judgments being formed. Several studies in the psychological literature have shown that people do not efficiently learn from the absence of cues, because non-occurrences are less salient and are harder to process than occurrences (e.g., Neisser 1963; Healy 1981; Treisman and Souther 1985; Pezdek, Maki, Valencia-Laver, Whetstone, Stoeckert, and Dougherty 1988; Treisman and Gormican 1988; Agostinelli, Sherman, Fazio, and Hearst 1986; Maki 1989; Hearst 1991; Henderson, Williams, Castelhano, and Falk 2003). The fact that people do not make optimal use of the information implicit in the non-receipt of cues suggests that they also are unlikely to make optimal use of the information implicit in cues that they have received but failed to process. So, ignoring the information item and failing to adjust for the fact that the item has been neglected often go hand in hand.

Evidence that people both neglect signals and do not adjust for the fact that they are neglecting them is provided by studies that show that the form of presentation of information affects individuals' judgments and decisions (see, e.g., Slovic 1972; Payne, Bettman, and Johnson 1993; and the review of Libby, Bloomfield, and Nelson 2002). Experimental studies have found that different presentations of equivalent information about a firm affect the valuations and trades of investors and experienced financial analysts. ${ }^{15}$ In principle, if an investor understood that, owing to limited attention, certain formats were hard to process, the investor could self-debias by, for example, mentally rearranging the format of presentation. However, such rearrangement itself requires mental processing.

15 Presentation effects have been found in a variety of financial reporting and disclosure contexts (Harper, Mister, and Strawser 1987; Hopkins 1996; Libby and Tan 1999; Hopkins, Houston, and Peters 2000; Hirst and Hopkins 1998; Dietrich, Kachelmeier, Kleinmuntz, and Linsmeier 2001). 
Furthermore, experimental research has found that the presentation of onesided arguments and evidence to subjects (called "jurors") asked to judge a legal dispute were biased in favor of the side they heard (Brenner, Koehler, and Tversky 1996). According to the authors, "The results indicate that people do not compensate sufficiently for missing information even when it is painfully obvious that the information available to them is incomplete" (p. 59).

Why don't individuals fully adjust beliefs about their own precisions to take into account the set of cues they are neglecting? Thinking about how the neglect of a cue creates bias or reduces precision itself requires cognitive processing. Indeed, it can be more cognitively costly to calculate how to adjust for the neglect of a relevant information item than to simply process the item in the first place. So, the same cognitive resource constraints that cause cue neglect often cause a failure to assess the consequences of that neglect. Kahneman (2003) discusses a large psychological literature on different systems of judgment: one slow, effortful, and logical, the other fast, intuitive, and heuristic. Inherent in the fact that people sometimes use faster, more intuitive means of forming judgments is that they do not fully undo the imperfections of heuristic decision-making. In consequence, even if on average the individual is correct, in those cases in which the cues he neglects are especially important, he will tend to overestimate the precision of his beliefs; and when the cues he neglects are minor, he will underestimate his precision.

Such miscalibration encourages investors who have neglected important cues to trade and influence price. Furthermore, an investor can form a valuation of a firm without necessarily recognizing that the other investors are using better information to form their valuations.

Informal behavioral explanations for anomalies have also sometimes assumed that investors who neglect public signals such as current-period earnings are important for price setting. For example, the seasonal-random-walk explanation for post-earnings announcement drift of Bernard and Thomas (1989) assumes that investors who focus on year-ago earnings neglect the latest earnings surprise. There are several possible reasons why an individual who neglects current-period earnings or its implications for the future would still trade actively. Some investors who focus on a firm's long-term business strategy and competitive environment may trade based upon long-term valuation targets without updating forecasts in response to every earnings report. ${ }^{16}$

There is evidence that some individual investors are net providers of liquidity to the market, absorbing the demand by institutions for trading immediacy (e.g., Kaniel, Saar, and Titman 2008). If institutions (perhaps for agency

16 Such a tendency may be reinforced by the practice of analysts of announcing "target" prices below which the stock is recommended as a good buy. Commonly repeated sound bites can reinforce the tendency of investors with limited attention to trade as contrarians. The business media often rails against "obsession" with short-term earnings, and in favor of "buying on the dips." An investor who updates less often can congratulate himself for "focusing on the long term." A naïve application of sound bites with high availability in the media is itself a possible consequence of limited attention. 
reasons) are willing to pay for trading immediacy, a naïve contrarian trading strategy can be profitable, on average. Indeed, contrarian U.S. individual investors earn positive excess returns in the month after their trades (Kaniel, Saar, and Titman 2008).

A naïve contrarian strategy of trading in opposition to market price movements without regard to their source will, on average, induce trading against earnings announcements. ${ }^{17}$ Even if a naïve contrarian strategy is profitable on average, it may on average be unprofitable conditional upon actual news arrival such as an earnings announcement. Thus, limited attention on the part of investors' traders who are following a generally reasonable contrarian strategy can induce unprofitable contrarian trading in response to earnings announcements.

A further reason why an investor with limited attention would actively trade as a contrarian to earnings news is that analysts, on average, do not fully adjust their earnings forecasts in response to earnings announcements (e.g., Abarbanell and Bernard 1992; Zhang 2008). Owing to limited attention, some investors may rely on analyst earnings forecasts without performing the additional cognitive processing needed to adjust for this state-contingent bias in analyst forecasts. The beliefs of such investors will therefore underreact to earnings surprises, just as analyst forecasts do. ${ }^{18}$ Consistent with this interpretation, there is evidence that firms that are followed by analysts whose forecasts are more responsive to earnings announcements have less postearnings announcement drift (Zhang 2008).

Furthermore, the intuition from standard securities market models suggests that even an investor who is aware of his own limited attention and rationally adjusts for it should trade based upon his expectations rather than withdrawing into autarky. In Section 3, we show that investors who ignore earnings can profit owing to the presence of noise/liquidity traders. Standard models of information and securities markets such as Grossman and Stiglitz (1976) provide the insight that, owing to liquidity or noise trading, prices aggregate information imperfectly, and in equilibrium contain noise-induced mispricing. As a result, even an informationally disadvantaged investor should trade based upon his beliefs rather than deferring blindly to market price. ${ }^{19}$ In a setting with limited attention, an isomorphic situation arises in which a set of investors has a kind of pseudo-private information. Attending to a public signal that some other investors neglect is analogous to observing a private signal. Neglecting

17 For example, since limit orders are triggered by moves in market price, placing such an order allows the investor to provide liquidity to the market without continuously monitoring prices.

18 A similar argument applies to investors who neglect accruals. Such investors may form beliefs based upon analysts' earnings forecasts, which underutilize the information contained in accruals (Teoh and Wong 2002).

19 In forming his beliefs, an investor combines any private signals he may possess (none, for an uninformed trader), together with the information implicit in market price. The weight on his own signals and prior is positive because market price is noisy. The noise in market price derives both from liquidity shocks and, if there are multiple private signals, from confounding between signals. 
a signal that other individuals attend to is akin to being uninformed about that signal. However, in standard models of information and securities markets, individuals with informational advantages and disadvantages all trade based upon their beliefs, and in so doing profit at the expense of liquidity traders.

Indeed, models that are ostensibly about private information are often interpreted in ways that are more consistent with individuals making different use of publicly available information. Discussions based on these models do not usually interpret private information as being limited to inside information (e.g., information obtained by espionage, eavesdropping, or persuading employees to leak information). Instead, investors become privately informed through some unspecified process_-presumably involving analysis of publicly available signals such as financial statements and media reports. This broader interpretation of Grossman and Stiglitz (1976) implicitly involves trade motivated by greater use of publicly available information by some investors than others.

To develop our implications simply, we assume that investors with limited attention do not incorporate market price into their beliefs. In reality, this assumption may apply to some investors, but similar results to those in our model could be derived in a setting in which investors with limited attention draw rational inferences from market prices that are noisy owing to liquidity trading. Such noise causes investors rationally to place less weight upon market price in updating beliefs, which would endogenize the conclusion that individuals with limited attention trade actively based upon their beliefs rather than deferring completely to market price.

Such an analysis would generally be quite similar to our model. The ability of inattentive investors to update based upon price should moderate the effects of limited attention. But it should not eliminate them, because noise would prevent price from fully revealing to inattentive investors the information they are otherwise neglecting.

There is other evidence that limited attention affects capital markets; indeed, Daniel, Hirshleifer, and Teoh (2002) suggest that limited attention may underlie an array of anomalous patterns in securities market trading and prices (e.g., Huberman and Regev 2001; Hou and Moskowitz 2005; Hong, Torous, and Valkanov 2007). Many short-horizon event studies confirm that stock markets react immediately to relevant news. Long-horizon event studies provide evidence suggesting that there is underreaction to various kinds of public news events (e.g., the review of Hirshleifer 2001). However, there has been a great deal of debate as to the appropriate methodology for testing market efficiency using long-run abnormal returns.

It can be argued that arbitrageurs such as hedge funds will eliminate almost all of the mispricing created by limited attention. However, a literature in behavioral finance and accounting has argued that arbitrage is limited by riskbearing capacity and market frictions (e.g., Pontiff 1996; Shleifer and Vishny 1997; Hirshleifer 2001; Lee 2001). Another constraint on arbitrage is the aggregate attentional capacity in the market (e.g., Peng 2005). Attention can be 
leveraged by such means as computers and financial intermediation, but even large institutions face trade-offs in allocating their attentional resources.

\section{Conclusion}

We provide a model of stock market misreactions to earnings-related information based upon limited investor attention. It is motivated by evidence of stock return predictability based upon earnings surprises and the level of earnings, accruals, and cash flows, including the striking fact that there are both underreactions and overreactions to different kinds of earnings-related information. To understand the sources of these return anomalies, it is important to be parsimonious in assumptions about psychological biases, to avoid overfitting the data. We therefore explore the consequences of a single psychological constraint, limited attention, which we use to derive a rich set of untested empirical implications.

We assume that some investors neglect information contained in the latest earnings surprise, and that some investors further neglect the information contained in accruals and cash flow. In equilibrium, there is underreaction to earnings surprises, because some investors do not attend to the newly arriving earnings news. Cash flows positively and accruals negatively predict future stock returns, because some investors do not impound the information contained in the division of earnings between cash flow and accruals. Since cash flow is more favorable than accruals as a forecaster of future earnings, high accruals are associated with overvaluation, and high cash flow with undervaluation. The model does not in general predict that either of the cash flow or accruals effects on future returns will completely subsume the other. We also find that the level of earnings predicts future stock returns when investors are inattentive toward earnings news. This predictability arises when inattentive investors stick to their beliefs based on the prior expectation of short-term earnings (e.g., analyst forecasts), instead of updating and improving the precision of their forecasts based on the realization of short-term earnings. Finally, we show that, when processing information is costly, in equilibrium some investors may actively trade yet choose not to attend to some public information. This may explain why inattentive investors can form incorrect expectations that influence price in the long run.

The model provides a rich set of new empirical implications. When some investors neglect earnings, and others attend to earnings but neglect accruals, price underreacts to earnings, but overreacts to accruals relative to cash flow. In consequence, there is stronger underreaction to cash flow than to earnings. Furthermore, if enough attention is paid to earnings, there is overreaction to accruals. A lower quality of accruals as an earnings forecaster (induced, for example, by earnings management) strengthens the accrual anomaly, but has an ambiguous effect on the cash flow anomaly. The more variable the accruals relative to cash flows, the stronger the cash flow anomaly relative to the accrual 
anomaly. The ratio of the cash flow effect to the accruals effect is stronger than the ratio of accruals variance to cash flow variance. Higher correlation between cash flows and accruals tends to weaken the accrual anomaly. In addition, owing to neglect of earnings news, the profit anomaly becomes stronger when there is less attention toward earnings news and expected earnings (such as analyst forecasts of short-term earnings) becomes a less accurate predictor of future earnings compared to actual short-term earnings.

Another appealing set of empirical implications is provided by events that shift attention to or away from the firm. For example, a greater number of distracting events such as earnings announcements by other firms is predicted to intensify both post-earnings announcement drift and the cash flow anomaly. The implications of shifts of attention toward or away from a firm for the accrual anomaly is less clear cut. Neglect of earnings components (cash flow vs. accruals) strengthens the accrual anomaly, whereas neglect of the earnings innovation itself weakens the accrual anomaly.

Our reconciliation of the drift and accruals effects is potentially consistent with some of the informal intuitions about investor "naïveté" offered in the empirical literature. It is of course reassuring that such insights can be captured within an equilibrium model. However, formal analysis does not entirely confirm casual intuition. For example, in a classic paper, Sloan (1996) argues that the accrual anomaly will be present if accruals are a weaker forecaster than cash flows of future earnings. We show here that, when investors are subject to limited attention, this is a necessary but not sufficient condition for the accrual anomaly. More importantly, our main contribution is to develop a unified framework based upon a well-established psychological constraint that offers a rich set of untested empirical predictions about earnings, cash flow, accruals, and stock market prices.

Our model is, of course, very stylized. A natural further direction of extension is to consider finer components of accruals and cash flow. An analysis similar to that developed here would show that overvaluation will be increasing with the level of an earnings component if that component is a relatively strong incremental forecaster of future earnings, and will be decreasing with that component if it is a weak incremental forecaster of future earnings. Thus, our approach is consistent with the evidence on earnings components and returns of Richardson et al. (2005) and Dechow and Ge (2006). Furthermore, it would be simple to apply such a generalized analysis to normal versus abnormal levels of accruals (where "normal" is evaluated relative to an industry or other benchmark), in order to develop predictions about how managerial discretion affects misvaluation as studied empirically in Teoh, Welch, and Wong (1998a,b) and others. Also, by adding another time period, the relation between the forecasting power of variables for short-term versus long-term earnings with misvaluation could be considered. The framework can be applied to investment-related anomalies as well. These and other possible extensions suggest that the modeling approach offered here potentially has a wide range of applicability to 
circumstances in which market misvaluation derives from investor neglect of publicly available financial information.

\section{Appendix}

Proof of proposition 7. It follows from Equation (25) that

$$
E\left[S_{2} \mid c_{1}, a_{1}\right]=E\left[S_{2}\right]+\left(1+\beta_{1}\right)\left(c_{1}-\bar{c}_{1}\right)+\left(1+\beta_{2}\right)\left(a_{1}-\bar{a}_{1}\right) .
$$

Substituting $E\left[S_{2} \mid e_{1}\right]$ and $E\left[S_{2} \mid c_{1}, a_{1}\right]$ in (10) with (18) and (A.1), date 1 stock price can be written as

$$
\begin{aligned}
S_{1}= & E\left[S_{2}\right]+\left[f^{a}\left(1+\beta_{1}\right)+f^{e}\left(1+\beta_{e_{2} e_{1}}\right)\right]\left(c_{1}-\bar{c}_{1}\right) \\
& +\left[f^{a}\left(1+\beta_{2}\right)+f^{e}\left(1+\beta_{e_{2} e_{1}}\right)\right]\left(a_{1}-\bar{a}_{1}\right)-A \operatorname{var}\left(S_{2}\right) x_{0} .
\end{aligned}
$$

From (A.2) and (25), the price change $S_{2}-S_{1}$ is

$$
\begin{aligned}
S_{2}-S_{1}= & {\left[\left(f^{u}+f^{e}\right)\left(1+\beta_{1}\right)-f^{e}\left(1+\beta_{e_{2} e_{1}}\right)\right]\left(c_{1}-\bar{c}_{1}\right) } \\
& +\left[\left(f^{u}+f^{e}\right)\left(1+\beta_{2}\right)-f^{e}\left(1+\beta_{e_{2} e_{1}}\right)\right]\left(a_{1}-\bar{a}_{1}\right) \\
& +\delta+A \operatorname{var}\left(S_{2}\right) x_{0} .
\end{aligned}
$$

Since $E\left[S_{1}\right]=E\left[S_{2}\right]$, the expected profit of an inattentive investor is

$$
E\left[\frac{E\left[S_{2}\right]-S_{1}}{A \operatorname{var}\left(S_{2}\right)}\left(S_{2}-S_{1}\right)\right]=\frac{\operatorname{cov}\left(-S_{1}, S_{2}-S_{1}\right)}{A \operatorname{var}\left(S_{2}\right)} .
$$

Using $S_{1}$ and $S_{2}-S_{1}$ given by (A.2) and (A.3) and simplifying some terms using the definition of $\beta_{e_{2} e_{1}}$ in (15), the covariance term can be written as follows:

$$
\begin{aligned}
\operatorname{cov}\left(-S_{1}, S_{2}-S_{1}\right)= & -f^{u} f^{e}\left(1+\beta_{e_{2} e_{1}}\right)^{2}\left(V_{a}+V_{c}+2 C\right) \\
& -f^{u} f^{a} \operatorname{var}\left(E\left[S_{2} \mid c_{1}, a_{1}\right]\right) \\
& -\frac{f^{a} f^{e}\left(\beta_{1}-\beta_{2}\right)^{2}\left(V_{c} V_{a}-C^{2}\right)}{\left(V_{a}+V_{c}+2 C\right)}+A^{2}\left(\operatorname{var}\left(S_{2}\right)\right)^{2} V_{x} .
\end{aligned}
$$

Since $V_{a}+V_{c}+2 C=V_{e}>0$ and $V_{c} V_{a} \geqslant C^{2}$, uninformed investors earn negative expected profits when there is no noise trading, i.e., $V_{x}=0$. However, the expected profit of an uninformed investor is positive when

$$
V_{x}>\frac{f^{u} f^{e}\left(1+\beta_{e_{2} e_{1}}\right)^{2}\left(V_{e}\right)^{2}+f^{u} f^{a} \operatorname{var}\left(E\left[S_{2} \mid c_{1}, a_{1}\right]\right) V_{e}+f^{a} f^{e}\left(\beta_{1}-\beta_{2}\right)^{2}\left(V_{c} V_{a}-C^{2}\right)}{A^{2}\left(\operatorname{var}\left(S_{2}\right)\right)^{2} V_{e}} .
$$

The expected trading profit of an investor attending only to earnings is

$$
E\left[\frac{E\left[S_{2} \mid e_{1}\right]-S_{1}}{A \operatorname{var}\left(S_{2}\right)}\left(S_{2}-S_{1}\right)\right]=\frac{\operatorname{cov}\left(E\left[S_{2} \mid e_{1}\right]-S_{1}, S_{2}-S_{1}\right)}{A \operatorname{var}\left(S_{2}\right)} .
$$

The equality follows from the fact that $E\left[E\left[S_{2} \mid e_{1}\right]\right]=E\left[S_{1}\right]=E\left[S_{2}\right]$. From (A.2) and (18),

$$
\begin{aligned}
E\left[S_{2} \mid e_{1}\right]-S_{1}= & {\left[\left(f^{u}+f^{a}\right)\left(1+\beta_{e_{2} e_{1}}\right)-f^{a}\left(1+\beta_{1}\right)\right]\left(c_{1}-\bar{c}_{1}\right) } \\
& +\left[\left(f^{u}+f^{a}\right)\left(1+\beta_{e_{2} e_{1}}\right)-f^{a}\left(1+\beta_{2}\right)\right]\left(a_{1}-\bar{a}_{1}\right)+A \operatorname{var}\left(S_{2}\right) x_{0} .
\end{aligned}
$$


From (A.3) and (A.8),

$$
\begin{aligned}
\operatorname{cov}\left(E\left[S_{2} \mid e_{1}\right]-S_{1}, S_{2}-S_{1}\right)= & \left(f^{u}\right)^{2}\left(1+\beta_{e_{2} e_{1}}\right)^{2} V_{e} \\
& -\frac{f^{a}\left(f^{u}+f^{e}\right)\left(\beta_{1}-\beta_{2}\right)^{2}\left(V_{c} V_{a}-C^{2}\right)}{V_{e}} \\
& +A^{2}\left(\operatorname{var}\left(S_{2}\right)\right)^{2} V_{x} .
\end{aligned}
$$

Investors attending only to earnings can earn positive expected profits owing to uninformed investors (the first term) and noise trading (the last term). The expected profit of an investor who attends to earnings is positive if and only if

$$
V_{x}>\frac{-\left(f^{u}\right)^{2}\left(1+\beta_{e_{2} e_{1}}\right)^{2}\left(V_{e}\right)^{2}+f^{a}\left(f^{u}+f^{e}\right)\left(\beta_{1}-\beta_{2}\right)^{2}\left(V_{c} V_{a}-C^{2}\right)}{A^{2}\left(\operatorname{var}\left(S_{2}\right)\right)^{2} V_{e}} .
$$

Thus, investors attending only to earnings can earn positive expected profits if there is a large amount of noise trading ( $V_{x}$ satisfying the above inequality).

\section{References}

Abarbanell, J. S., and V. L. Bernard. 1992. Tests of Analysts' Overreaction/Underreaction to Earnings Information as an Explanation for Anomalous Stock Price Behavior. Journal of Finance 47:1181-207.

Agostinelli, G., S. J. Sherman, R. H. Fazio, and E. S. Hearst. 1986. Detecting and Identifying Change: Additions versus Deletions. Journal of Experimental Psychology: Human Perception and Performance 12:445-54.

Ash, R. B. 1972. Real Analysis and Probability. Probability and Mathematical Statistics Series. New York: Academic Press.

Bagnoli, M., M. B. Clement, and S. G. Watts. 2005. Around-the-clock Media Coverage and the Timing of Earnings Announcements. Working Paper, Purdue University.

Balakrishnan, K., E. Bartov, and L. Faurel. 2010. Post-loss/profit Announcement Drift. Journal of Accounting and Economics 50:20-41.

Ball, R., and P. Brown. 1968. An Empirical Evaluation of Accounting Income Numbers. Journal of Accounting Research 6:159-77.

Bartov, E., I. Krinsky, and S. Radhakrishnan. 2000. Investor Sophistication and Patterns in Stock Returns after Earnings Announcements. Accounting Review 75:43-63.

Bernard, V. L., and J. K. Thomas. 1989. Post-earnings Announcement Drift: Delayed Price Response or Risk Premium? Journal of Accounting Research Supplement 27:1-48.

Brenner, L. A., D. J. Koehler, and A. Tversky. 1996. On the Evaluation of One-sided Evidence. Journal of Behavioral Decision Making 9:59-70.

Chen, C. 2009. Earnings Persistence and Stock Price Under- and Overreaction. Working Paper, University of Waterloo.

Chen, L., R. Novy-Marx, and L. Zhang. 2010. An Alternative Three-factor Model. Working Paper, Washington University-St. Louis.

Chen, S., M. L. DeFond, and C. W. Park. 2002. Voluntary Disclosure of Balance Sheet Information in Quarterly Earnings Announcements. Journal of Accounting and Economics 33:229-51.

Cohen, A. J. 2005. Aristotle on Investment Decision Making. Financial Analyst Journal 61:29-41.

Collins, D., and P. Hribar. 2000. Earnings-based and Accruals-based Anomalies: One Effect or Two? Journal of Accounting and Economics 29:101-23.

Collins, D. W., G. Gong, and P. Hribar. 2003. Investor Sophistication and the Mispricing of Accruals. Review of Accounting Studies 8:251-76. 
Daniel, K. D., D. Hirshleifer, and S. H. Teoh. 2002. Investor Psychology in Capital Markets: Evidence and Policy Implications. Journal of Monetary Economics 49:139-209.

Dechow, P. 1994. Accounting Earnings and Cash Flows as Measures of Firm Performance: The Role of Accounting Accruals. Journal of Accounting and Economics 18:3-42.

Dechow, P. M., and W. Ge. 2006. The Persistence of Earnings and Cash Flows and the Role of Special Items: Implications for the Accrual Anomaly. Review of Accounting Studies 11:253-96.

DeGeorge, F., J. Patel, and R. Zeckhauser. 1999. Earnings Management to Exceed Thresholds. Journal of Business 72:1-34.

DellaVigna, S., and J. Pollet. 2009. Investor Inattention and Friday Earnings Announcements. Journal of Finance 64:709-49.

DellaVigna, S., and J. M. Pollet. 2007. Demographics and Industry Returns. American Economic Review 97: $1667-702$.

Diamond, D. W., and R. E. Verrecchia. 1981. Information Aggregation in a Noisy Rational Expectations Economy. Journal of Financial Economics 9:221-35.

Dietrich, J. R., S. J. Kachelmeier, D. N. Kleinmuntz, and T. J. Linsmeier. 2001. Market Efficiency, Bounded Rationality, and Supplemental Business Reporting Disclosures. Journal of Accounting Research 39:243-68.

Dong, M., D. Hirshleifer, S. Richardson, and S. H. Teoh. 2006. Does Investor Misvaluation Drive the Takeover Market? Journal of Finance 61:725-62.

Francis, J., D. Pagach, and J. Stephan. 1992. The Stock Market Response to Earnings Announcements Released During Trading versus Nontrading Periods. Journal of Accounting Research 30:165-84.

Gabaix, X., and D. Laibson. 2005. Bounded Rationality and Directed Cognition. Working Paper, MIT and Harvard University.

Grossman, S. J., and J. E. Stiglitz. 1976. Information and Competitive Price Systems. American Economic Review 66:246-53.

Gu, Z., P. C. Jain, and S. Ramnath. 2005. Revenue Surprises and Expense Surprises: Information and Use. Working Paper, Carnegie Mellon University.

Harper, R. M. J., W. G. Mister, and J. R. Strawser. 1987. The Impact of New Pension Disclosure Rules on Perceptions. Journal of Accounting Research 25:327-30.

Healy, A. F. 1981. The Effects of Visual Similarity on Proofreading for Misspellings. Memory and Cognition 9:453-60.

Hearst, E. 1991. Psychology and Nothing. American Scientist 79:432-43.

Henderson, J. M., C. C. Williams, M. S. Castelhano, and R. J. Falk. 2003. Eye Movements and Picture Processing During Recognition. Perception \& Psychophysics 65:725-34.

Hirshleifer, D. 2001. Investor Psychology and Asset Pricing. Journal of Finance 64:1533-97.

Hirshleifer, D., S. S. Lim, and S. H. Teoh. 2008. Disclosure to an Audience with Limited Attention. Working Paper, Merage Business School, UC Irvine.

2009. Driven to Distraction: Extraneous Events and Underreaction to Earnings News. Journal of Finance 64:2289-325.

Hirshleifer, D., and S. H. Teoh. 2003. Limited Attention, Information Disclosure, and Financial Reporting. Journal of Accounting \& Economics 36:337-86.

Hirst, D., and P. E. Hopkins. 1998. Comprehensive Income Reporting and Analysts' Valuation Judgments. Journal of Accounting Research Supplement 36:47-75.

Hong, H., W. Torous, and R. Valkanov. 2007. Do Industries Lead Stock Markets? Journal of Financial Economics 83:367-96. 
Hopkins, P. 1996. The Effect of Financial Statement Classification of Hybrid Financial Instruments on Financial Analysts' Stock Price Judgments. Journal of Accounting Research 34:33-50.

Hopkins, P. E., R. W. Houston, and M. F. Peters. 2000. Purchase, Pooling, and Equity Analysts' Valuation Judgments. Accounting Review 75:257-81.

Hou, K., and T. Moskowitz. 2005. Market Frictions, Price Delay, and the Cross-section of Expected Returns. Review of Financial Studies 18:981-1020.

Huberman, G., and T. Regev. 2001. Contagious Speculation and a Cure for Cancer. Journal of Finance 56:38796.

Iliev, P., and I. Welch. 2010. A Model of Operational Slack: The Short-run, Medium-run, and Long-run Consequences of Limited Attention. Working Paper, Pennsylvania State University and Brown University.

Jegadeesh, N., and J. Livna. 2006. Revenue Surprises and Stock Returns. Journal of Accounting and Economics 41:147-71.

Kahneman, D. 1973. Attention and Effort. Englewood Cliffs, NJ: Prentice-Hall. 58:697-720. 2003. A Perspective on Judgment and Choice: Mapping Bounded Rationality. American Psychologist

Kandel, E., and N. D. Pearson. 1995. Differential Interpretation of Public Signals and Trade in Speculative Markets. Journal of Political Economy 103:831-72.

Kaniel, R., G. Saar, and S. Titman. 2008. Individual Investor Trading and Stock Returns. Journal of Finance 63:273-310.

Lee, C. M. 2001. Market Efficiency and Accounting Research: A Discussion of "Capital Market Research in Accounting" by S. P. Kothari. Journal of Accounting \& Economics 31:233-53.

Lee, C. M., J. Myers, and B. Swaminathan. 1999. What Is the Intrinsic Value of the Dow? Journal of Finance 54:1693-741.

Lerman, A. 2011. Individual Investors' Attention to Accounting Information: Message Board Discussions. Working Paper, Yale School of Management.

Libby, R., R. Bloomfield, and M. W. Nelson. 2002. Experimental Research in Financial Accounting. Accounting, Organizations, and Society 27:775-810.

Libby, R., and H.-T. Tan. 1999. Analysts' Reactions to Warnings of Negative Earnings. Journal of Accounting Research 37:415-36.

Livnat, J. 2003. Differential Persistence of Extremely Negative and Positive Earnings Surprises: Implications for the Post-earnings Announcement Drift. Working Paper, New York University.

Maki, R. H. 1989. Recognition of Added and Deleted Details in Scripts. Memory and Cognition 17:274-82.

Neisser, U. 1963. Decision-time without Reaction-time: Experiments in Visual Scanning. American Journal of Psychology 76:376-85.

Ohlson, J. 1995. Earnings, Book Values, and Dividends in Equity Valuation. Contemporary Accounting Research 11:661-87.

Payne, J., J. Bettman, and E. Johnson. 1993. The Adaptive Decisionmaker (1st ed.). Cambridge, UK: Cambridge University Press.

Peng, L. 2005. Learning with Information Capacity Constraints. Journal of Financial and Quantitative Analysis 40:307-29.

Peng, L., and W. Xiong. 2002. Time to Digest and Volatility Dynamics. Working Paper, City University of New York.

2006. Investor Attention, Overconfidence, and Category Learning. Journal of Financial Economics 80:563-602. 
Pezdek, K., R. Maki, D. Valencia-Laver, T. Whetstone, J. Stoeckert, and T. Dougherty. 1988. Picture Memory: Recognizing Added and Deleted Details. Journal of Experimental Psychology: Learning, Memory, and Cognition 14:468-76.

Pincus, M., S. Rajgopal, and M. Venkatachalam. 2007. The Accrual Anomaly: International Evidence. Accounting Review 82:169-203.

Pontiff, J. 1996. Costly Arbitrage: Evidence from Closed-end Funds. Quarterly Journal of Economics 111: $1135-51$.

Richardson, S. A., R. G. Sloan, M. T. Soliman, and I. Tuna. 2005. Accrual Reliability, Earnings Persistence, and Stock Prices. Journal of Accounting and Economics 39:437-85.

Shleifer, A., and R. Vishny. 1997. The Limits to Arbitrage. Journal of Finance 52:35-55.

Sloan, R. 1996. Do Stock Prices Fully Reflect Information in Accruals and Cash Flows about Future Earnings? Accounting Review 71:289-315.

Slovic, P. 1972. From Shakespeare to Simon: Speculations—and Some Evidence-About Man's Ability to Process Information. Oregon Research Institute Research Monograph 12.

Teoh, S. H., I. Welch, and T. J. Wong. 1998. Earnings Management and the Long-term Market Performance of Initial Public Offerings. Journal of Finance 53:1935-74.

1998. Earnings Management and the Underperformance of Seasoned Equity Offerings. Journal of Financial Economics 50:63-99.

Teoh, S. H., and T. Wong. 2002. Why Do New Issues and High Accrual Firms Underperform? The Role of Analysts' Credulity, Review of Financial Studies 15:869-900.

Treisman, A., and S. Gormican. 1988. Feature Analysis in Early Vision: Evidence from Search Asymmetries. Psychological Review 95:15-48.

Treisman, A., and J. Souther. 1985. Search Asymmetry: A Diagnostic for Preattentive Processing of Separable Features. Journal of Experimental Psychology: General 114:285-310.

Verrecchia, R. E. 2001. Essays on Disclosure. Journal of Accounting and Economics 32:97-180.

Zhang, Y. 2008. Analysts' Responsiveness and Market Underreaction to Earnings Announcements. Journal of Accounting and Economics 46:201-15. 